Article

\title{
Prediction of First-Year Corrosion Losses of Carbon Steel and Zinc in Continental Regions
}

\author{
Yulia M. Panchenko * and Andrey I. Marshakov
}

A.N. Frumkin Institute of Physical Chemistry and Electrochemistry, Russian Academy of Sciences, Moscow 119071, Russia; mar@ipc.rssi.ru

* Correspondence: panchenkoyum@mail.ru

Academic Editor: Douglas Ivey

Received: 18 February 2017; Accepted: 13 April 2017; Published: 18 April 2017

\begin{abstract}
Dose-response functions (DRFs) developed for the prediction of first-year corrosion losses of carbon steel and zinc $\left(K_{1}\right)$ in continental regions are presented. The dependences of mass losses on $\mathrm{SO}_{2}$ concentration, $\mathrm{K}=f\left(\left[\mathrm{SO}_{2}\right]\right)$, obtained from experimental data, as well as nonlinear dependences of mass losses on meteorological parameters, were taken into account in the development of the DRFs. The development of the DRFs was based on the experimental data from one year of testing under a number of international programs: ISO CORRAG, MICAT, two UN/ECE programs, the Russian program in the Far-Eastern region, and data published in papers. The paper describes predictions of $K_{1}$ values of these metals using four different models for continental test sites under UN/ECE, RF programs and within the MICAT project. The predictions of $K_{1}$ are compared with experimental $K_{1}$ values, and the models presented here are analyzed in terms of the coefficients used in the models.
\end{abstract}

Keywords: carbon steel; zinc; modeling studies; atmospheric corrosion

\section{Introduction}

Predictions of the corrosion mass losses $(K)$ of structural metals, in general for a period not exceeding 20 years, are made using the power function:

$$
K=K_{1} \tau^{\mathrm{n}}
$$

where $K_{1}$ represents the corrosion losses for the first year, $g / \mathrm{m}^{2}$ or $\mu \mathrm{m} ; \tau$ is the test time in years; and $n$ is a coefficient that characterizes the protective properties of corrosion products. The practical applications of Equation (1) for particular test locations in various regions of the world and the methods for $n$ calculation are summarized in [1-8].

The power linear function that is believed to provide the most reliable predictions for any period of time and in any region of the world was suggested in $[9,10]$. Corrosion obeys a power law (Equation (1)) during an initial period and a linear law after the stationary stage starts. The total corrosion losses of metals for any period of time during the stationary stage can be calculated using Equation (2):

$$
K=K_{\mathrm{st}}+\alpha\left(\tau-\tau_{\mathrm{st}}\right)
$$

where $K_{\text {st }}$ stands for corrosion losses over the initial period calculated by Equation (1), $g / \mathrm{m}^{2}$ or $\mu \mathrm{m}$; $\tau_{\text {st }}$ is the year when stabilization begins; and $\alpha$ is the yearly gain in corrosion losses of metals during the stationary stage in $\mathrm{g} /\left(\mathrm{m}^{2}\right.$ year $)$ or $\mu \mathrm{m} /$ year.

The differences in the predictions of corrosion losses by Equations (1) and (2) consist of different estimates of $\tau_{\text {st }}, \alpha$, and $n$ values for test locations with various corrosivity and atmosphere types. According to [10], $\tau_{\text {st }}$ equals 20 years. The $n$ values are given per atmosphere type, irrespective of the 
atmosphere corrosivity within a particular type. In [9], $\tau_{\text {st }}=6$ years, and equations for $n$ calculations based on the corrosivity of various atmosphere types are suggested. In $[9,10]$, the $\alpha$ values are equal to the instantaneous corrosion rate at $\tau_{\text {st }}$.

Furthermore, various types of dose-response functions (DRFs) have been developed for long-term predictions of $K$; these can be used for certain territories or for any region of the world [11-17]. It should be noted that DRFs are power functions and have an advantage in that they provide predictions of first-year corrosion losses $\left(K_{1}\right)$ based on yearly-average meteorological and aerochemical atmosphere parameters. The power-linear function uses $K_{1}$ values that should match the yearly-average corrosivity parameters of the test site atmosphere. The $K_{1}$ values can be determined by repeated natural yearly tests in each location, which require significant expense and ISO 9223:2012(E) presents equations for the calculation of $K_{1}$ of structural metals for any atmosphere types [18].

Recently, one-year and long-term predictions have been performed using models based on an artificial neural network (ANN) [19-23]. Their use is undoubtedly a promising approach in the prediction of atmospheric corrosion. The ANN "training" stage is programmed so as to obtain the smallest prediction error. Linear and nonlinear functions are used for $K$ or $K_{1}$ prediction by means of an ANN. Using an ANN, the plots of $K\left(K_{1}\right)$ versus specific corrosivity parameters can be presented visually as 2D or 3D graphs [19]. Despite the prospects of $K$ prediction using ANNs, DRF development for certain countries (territories) is an ongoing task. The analytical form of DRFs is most convenient for application by a broad circle of experts who predict the corrosion resistance of materials in structures.

DRF development is based on statistical treatment, regression analysis of experimental data on $K_{1}$, and corrosivity parameters of atmospheres in numerous test locations. All DRFs involve a prediction error that is characterized, e.g., by the $R^{2}$ value or by graphical comparison in coordinates of predicted and experimental $K_{1}$. However, comparisons of the results on $K_{1}$ predictions based on different DRFs for large territories have not been available to date. Furthermore, the DRFs that have been developed assume various dependences of $\mathrm{K}$ on $\mathrm{SO}_{2}$ concentration; however, the shape of the $K=f\left(\mathrm{SO}_{2}\right)$ function was not determined by analysis of data obtained in a broad range of atmosphere meteorological parameters.

The main purpose of this paper is to perform a mathematical estimate of the $K=f\left(\mathrm{SO}_{2}\right)$ dependence for carbon steel and zinc, popular structural materials, and to develop new DRFs for $K_{1}$ prediction based on the $K=f\left(\mathrm{SO}_{2}\right)$ dependences obtained and the meteorological corrosivity parameters of the atmosphere. Furthermore, we will compare the $K_{1}$ predictions obtained by the new and previously developed DRFs for any territories of the world, as well as analyze the DRFs based on the values of the coefficients in the equations.

\section{Results}

\subsection{Development of DRFs for Continental Territories}

To develop DRFs, we used the experimental data from all exposures for a one-year test period in continental locations under the ISO CORRAG international program [24], the MICAT project [11,25], the UN/ECE program [12,14], the Russian program [26], and the program used in [19]. The test locations for the UN/ECE program and the MICAT project are presented in Table 1. The corrosivity parameters of the test site atmospheres and the experimental $K_{1}$ values obtained in four one-year exposures under the UN/ECE program are provided in Table 2, those obtained in three one-year exposures under the MICAT project are given in Table 3, and those obtained in the RF program are provided in Table 4. Cai et al. [19] report a selection of data from various literature sources. Of this selection, we use only the experimental data for continental territories that are shown in Table 5 . The test results under the ISO CORRAG program [24] are not included in this paper because they lack the atmosphere corrosivity parameters required for $K_{1}$ prediction. We used them simply to determine the $K=f\left(\mathrm{SO}_{2}\right)$ dependences for steel and zinc. 
Table 1. Countries, names, and codes of test locations.

\begin{tabular}{|c|c|c|c|c|c|}
\hline \multicolumn{3}{|c|}{ MICAT Project } & \multicolumn{3}{|c|}{ UN/ECE Program } \\
\hline Country & Test Location & Designation & Country & Test Location & Designation \\
\hline Argentina & Villa Martelli & A2 & Czech Republic & Prague & CS1 \\
\hline Argentina & Iguazu & A3 & Czech Republic & Kasperske Hory & CS2 \\
\hline Argentina & San Juan & A4 & Czech Republic & Kopisty & CS3 \\
\hline Argentina & La Plata & A6 & Finland & Espoo & FIN4 \\
\hline Brasil & Caratinga & B1 & Finland & Ähtäri & FIN5 \\
\hline Brasil & Sao Paulo & B6 & Finland & Helsinki Vallila & FIN6 \\
\hline Brasil & Belem & B8 & Germany & Waldhof Langenbrügge & GER7 \\
\hline Brasil & Brasilia & B10 & Germany & Aschaffenburg & GER8 \\
\hline Brasil & Paulo Afonso & B11 & Germany & Langenfeld Reusrath & GER9 \\
\hline Brasil & Porto & B12 & Germany & Bottrop & GER10 \\
\hline Colombia & San Pedro & $\mathrm{CO} 2$ & Germany & Essen Leithe & GER11 \\
\hline Colombia & Cotove & $\mathrm{CO} 3$ & Germany & Garmisch Partenkirchen & GER12 \\
\hline Ecuador & Guayaquil & EC1 & Netherlands & Eibergen & NL18 \\
\hline Ecuador & Riobamba & EC2 & Netherlands & Vredepeel & NL19 \\
\hline Spain & Leon & E1 & Netherlands & Wijnandsrade & NL20 \\
\hline Spain & Tortosa & E4 & Norway & Oslo & NOR21 \\
\hline Spain & Granada & E5 & Norway & Birkenes & NOR23 \\
\hline Spain & Arties & E8 & Sweden & Stockholm South & SWE24 \\
\hline Mexico & Mexico (a) & M1 & Sweden & Stockholm Centre & SWE25 \\
\hline Mexico & Mexico (b) & M2 & Sweden & Aspvreten & SWE26 \\
\hline Mexico & Cuernavaca & M3 & Spain & Madrid & SPA31 \\
\hline Mexico & San Luis Potosi & PE4 & Spain & Toledo & SPA33 \\
\hline Peru & Arequipa & PE5 & Russian Federation & Moscow & RUS34 \\
\hline Peru & Arequipa & PE6 & Estonia & Lahemaa & EST35 \\
\hline Peru & Pucallpa & U1 & Canada & Dorset & CAN37 \\
\hline Uruguay & Trinidad & U3 & USA & Research Triangle Park & US38 \\
\hline - & - & - & USA & Steubenville & US39 \\
\hline
\end{tabular}

Table 2. Atmosphere corrosivity parameters of test locations, first-year corrosion losses of carbon steel and zinc $\left(K_{1}, \mathrm{~g} / \mathrm{m}^{2}\right)$ under the UN/ECE program, and numbers of test locations in the order of increasing $K_{1}$.

\begin{tabular}{|c|c|c|c|c|c|c|c|c|c|c|}
\hline \multirow{2}{*}{ Designation } & \multirow{2}{*}{$T,{ }^{\circ} \mathrm{C}$} & \multirow{2}{*}{$R H, \%$} & \multirow{2}{*}{$\begin{array}{c}\text { TOW, } \\
\text { Hours/a }\end{array}$} & \multirow{2}{*}{$\begin{array}{l}\text { Prec, } \\
\mathrm{mm} / \mathrm{a}\end{array}$} & \multirow{2}{*}{$\begin{array}{l}{\left[\mathrm{SO}_{2}\right],} \\
\mu \mathrm{g} / \mathrm{m}^{3}\end{array}$} & \multirow{2}{*}{$\begin{array}{l}{\left[\mathrm{H}^{+}\right],} \\
\mathrm{mg} / \mathrm{L}\end{array}$} & \multicolumn{2}{|c|}{ Steel } & \multicolumn{2}{|c|}{ Zinc } \\
\hline & & & & & & & $\mathrm{g} / \mathrm{m}^{2}$ & No. & $\mathrm{g} / \mathrm{m}^{2}$ & No. \\
\hline CS1 & 9.5 & 79 & 2830 & 639.3 & 77.5 & - & 438.0 & 76 & 14.89 & 92 \\
\hline CS1 & 10.3 & 74 & 2555 & 380.8 & 58.1 & 0.0221 & - & - & 6.98 & 45 \\
\hline CS1 & 9.1 & 73 & 2627 & 684.3 & 41.2 & 0.0714 & 270.7 & 64 & 7.78 & 53 \\
\hline CS1 & 9.8 & 77 & 3529 & 581.1 & 32.1 & 0.0342 & 241.0 & 58 & 5.69 & 31 \\
\hline CS2 & 7.0 & 77 & 3011 & 850.2 & 19.7 & - & 224.0 & 51 & 8.95 & 65 \\
\hline CS2 & 7.4 & 76 & 3405 & 703.4 & 25.6 & 0.045 & - & - & 7.99 & 58 \\
\hline CS2 & 6.6 & 73 & 2981 & 921 & 17.9 & 0.1921 & 152.9 & 33 & 6.77 & 44 \\
\hline CS2 & 7.2 & 74 & 3063 & 941.2 & 12.2 & 0.0366 & 148.2 & 30 & 3.46 & 4 \\
\hline CS3 & 9.6 & 73 & 2480 & 426.4 & 83.3 & - & 557.0 & 77 & 16.41 & 94 \\
\hline CS3 & 9.9 & 72 & 2056 & 416.6 & 78.4 & 0.0242 & - & - & 11.59 & 87 \\
\hline CS3 & 8.9 & 71 & 2866 & 431.6 & 49 & 0.058 & 350.2 & 73 & 11.74 & 88 \\
\hline CS3 & 9.7 & 75 & 2759 & 512.7 & 49.2 & 0.0567 & 351.8 & 74 & 12.17 & 89 \\
\hline FIN4 & 5.9 & 76 & 3322 & 625.9 & 18.6 & - & 271.0 & 63 & - & - \\
\hline FIN4 & 6.4 & 80 & 4127 & 657 & 13.9 & 0.0392 & - & - & 8.42 & 62 \\
\hline FIN4 & 5.6 & 79 & 3446 & 754.6 & 2.3 & 0.0231 & 130.3 & 21 & 5.18 & 25 \\
\hline FIN4 & 6.0 & 80 & 3607 & 698.1 & 2.6 & 0.0334 & 120.9 & 20 & 4.68 & 19 \\
\hline FIN5 & 3.1 & 78 & 2810 & 801.3 & 6.3 & - & 132.0 & 23 & 8.92 & 66 \\
\hline FIN5 & 3.9 & 80 & 3342 & 670.7 & 1.8 & 0.0271 & - & - & 7.70 & 52 \\
\hline FIN5 & 3.4 & 81 & 2994 & 609.7 & 0.9 & 0.0201 & 48.4 & 4 & 6.62 & 41 \\
\hline FIN5 & 3.9 & 83 & 3324 & 675.4 & 0.8 & 0.0247 & 59.3 & 5 & 4.61 & 16 \\
\hline
\end{tabular}


Table 2. Cont.

\begin{tabular}{|c|c|c|c|c|c|c|c|c|c|c|}
\hline \multirow{2}{*}{ Designation } & \multirow{2}{*}{$T,{ }^{\circ} \mathrm{C}$} & \multirow{2}{*}{$R H, \%$} & \multirow{2}{*}{$\begin{array}{c}\text { TOW, } \\
\text { Hours/a }\end{array}$} & \multirow{2}{*}{$\begin{array}{l}\text { Prec, } \\
\mathrm{mm} / \mathrm{a}\end{array}$} & \multirow{2}{*}{$\begin{array}{l}{\left[\mathrm{SO}_{2}\right],} \\
\mu \mathrm{g} / \mathrm{m}^{3}\end{array}$} & \multirow{2}{*}{$\begin{array}{l}{\left[\mathrm{H}^{+}\right]} \\
\mathrm{mg} / \mathrm{L}\end{array}$} & \multicolumn{2}{|c|}{ Steel } & \multicolumn{2}{|c|}{ Zinc } \\
\hline & & & & & & & $\mathrm{g} / \mathrm{m}^{2}$ & No. & $\mathrm{g} / \mathrm{m}^{2}$ & No. \\
\hline FIN6 & 6.3 & 78 & 3453 & 673.1 & 20.7 & - & 273.0 & 65 & - & - \\
\hline FIN6 & 6.8 & 80 & 4017 & 665.6 & 15.3 & 0.0554 & - & - & 9.29 & 70 \\
\hline FIN6 & 6.2 & 78 & 3360 & 702.4 & 4.8 & 0.0221 & 162.2 & 34 & 5.69 & 33 \\
\hline FIN6 & 6.6 & 76 & 3288 & 649.2 & 5.5 & 0.0139 & 195.8 & 44 & 5.62 & 30 \\
\hline GER7 & 9.3 & 80 & 4561 & 630.6 & 13.7 & - & 264.0 & 62 & - & - \\
\hline GER7 & 10.2 & 80 & 4390 & 499.7 & 11 & 0.0358 & - & - & 7.85 & 56 \\
\hline GER7 & 8.9 & 81 & 4382 & 624.4 & 8.2 & 0.0342 & 230.9 & 53 & 9.07 & 68 \\
\hline GER7 & 9.5 & 81 & 4676 & 595.6 & 3.9 & 0.0265 & 166.1 & 36 & 4.25 & 13 \\
\hline GER8 & 12.3 & 77 & 4282 & 626.9 & 23.7 & - & 213.0 & 48 & - & - \\
\hline GER8 & 12.2 & 67 & 2541 & 655.4 & 14.2 & 0.0411 & - & - & 4.68 & 18 \\
\hline GER8 & 11.4 & 64 & 3563 & 561.2 & 12.6 & 0.0183 & 116.2 & 17 & 5.18 & 26 \\
\hline GER8 & 11.6 & 65 & 2359 & 779 & 9.6 & - & 141.2 & 27 & 4.10 & 12 \\
\hline GER9 & 10.8 & 77 & 4220 & 782.9 & 24.5 & - & 293.0 & 69 & - & - \\
\hline GER9 & 11.7 & 80 & 4940 & 697.6 & 20.3 & 0.0366 & - & - & 6.62 & 40 \\
\hline GER9 & 10.7 & 79 & 4437 & 619.1 & 16.3 & 0.0291 & 230.9 & 54 & 9.07 & 69 \\
\hline GER9 & 11.4 & 81 & 5210 & 841 & 11.1 & 0.0278 & 209.8 & 47 & 7.63 & - \\
\hline GER10 & 11.2 & 75 & 4077 & 873.8 & 50.6 & - & 373.0 & 75 & - & - \\
\hline GER10 & 12 & 76 & 4107 & 696.6 & 48.5 & 0.0253 & - & - & 10.66 & 81 \\
\hline GER10 & 10.3 & 78 & 4201 & 707.3 & 41.6 & 0.0211 & 347.1 & 72 & 15.34 & 93 \\
\hline GER10 & 11.8 & 80 & 4930 & 912.9 & 30.2 & 0.0334 & 294.1 & 70 & 7.85 & 55 \\
\hline GER11 & 10.5 & 79 & 4537 & 713.1 & 30.3 & - & 342.0 & 71 & - & - \\
\hline GER11 & 11.5 & 77 & 4040 & 644.5 & 25.6 & 0.042 & - & - & 9.72 & 73 \\
\hline GER11 & 10.1 & 79 & 4120 & 683.6 & 22.9 & 0.0253 & 293.3 & 68 & 11.45 & 86 \\
\hline GER11 & 10.9 & 78 & 4632 & 889.3 & 16.2 & 0.0247 & 241.0 & 57 & 7.06 & 46 \\
\hline GER12 & 8.0 & 82 & 4989 & 1491.5 & 9.4 & - & 133.0 & 24 & 8.35 & 61 \\
\hline GER12 & 7.3 & 82 & 4201 & 1183.1 & 6.1 & 0.0171 & - & - & 7.27 & 49 \\
\hline GER12 & 7.1 & 84 & 4545 & 1552.4 & 3.2 & 0.0018 & 89.7 & 9 & 7.20 & 48 \\
\hline GER12 & 7.4 & 83 & 4375 & 1503 & 2.4 & - & 85.0 & 8 & 3.74 & 9 \\
\hline NL18 & 9.9 & 83 & 5459 & 904.2 & 10.1 & - & 232.0 & 55 & 9.93 & 76 \\
\hline NL18 & 10.9 & 79 & 4482 & 705.9 & 8.5 & 0.0046 & - & - & 8.14 & 59 \\
\hline NL18 & 9.5 & 82 & 4808 & 872.8 & 7.4 & 0.004 & 204.4 & 45 & 7.92 & 57 \\
\hline NL18 & 10.3 & 83 & 5358 & 987.1 & 4.7 & 0.0366 & 144.3 & 28 & 4.75 & 20 \\
\hline NL19 & 10.3 & 81 & 5354 & 845 & 13 & - & 283.0 & 66 & - & - \\
\hline NL19 & 11 & 81 & 4969 & 569.1 & 9.9 & 0.0049 & - & - & 9.07 & 67 \\
\hline NL19 & 10 & 82 & 5084 & 749.2 & 8.3 & 0.0021 & 238.7 & 56 & 11.09 & 84 \\
\hline NL19 & 10.9 & 83 & 5454 & 828.9 & 4.5 & - & 180.2 & 39 & - & - \\
\hline NL20 & 10.3 & 81 & 5125 & 801.3 & 13.7 & - & 259.0 & 59 & - & - \\
\hline NL20 & 11.1 & 77 & 4424 & 608.8 & 10.3 & 0.0106 & - & - & 10.22 & 77 \\
\hline NL20 & 10.1 & 81 & 4688 & 679.6 & 9.3 & 0.0113 & 205.1 & 46 & 11.38 & 85 \\
\hline NL20 & 11.1 & 82 & 5141 & 789.9 & 5.8 & 0.0038 & 172.4 & 37 & 6.34 & 37 \\
\hline NOR21 & 7.6 & 70 & 2673 & 1023.8 & 14.4 & - & 229.0 & 52 & - & - \\
\hline NOR21 & 8.8 & 70 & 2864 & 526.6 & 7.9 & 0.0326 & - & - & 5.69 & 32 \\
\hline NOR21 & 7.7 & 68 & 2471 & 440.1 & 6 & 0.0156 & 134.9 & 25 & 6.70 & 43 \\
\hline NOR21 & 7.5 & 69 & 2827 & 680 & 2.9 & 0.0136 & 100.6 & 11 & 3.53 & 7 \\
\hline NOR23 & 6.5 & 80 & 4831 & 2144.3 & 1.3 & - & 194.0 & 43 & - & - \\
\hline NOR23 & 7.4 & 77 & 4193 & 1762.2 & 0.9 & 0.042 & - & - & 8.50 & 63 \\
\hline NOR23 & 5.9 & 75 & 3341 & 1188.6 & 0.7 & 0.0374 & 131.8 & 22 & 10.58 & 80 \\
\hline NOR23 & 6.4 & 76 & 3779 & 1419.7 & 0.7 & 0.0326 & 109.2 & 15 & 5.04 & 24 \\
\hline SWE24 & 7.6 & 78 & 3959 & 531 & 16.8 & - & 264.0 & 61 & 10.36 & 79 \\
\hline SWE24 & 8.7 & 70 & 3074 & 473.2 & 8.4 & 0.0366 & - & - & 6.12 & 35 \\
\hline SWE24 & 7 & 70 & 2580 & 577 & 5.7 & 0.043 & 120.1 & 18 & 4.54 & 15 \\
\hline SWE24 & 7.5 & 73 & 3160 & 580.6 & 4.2 & 0.0231 & 103.0 & 13 & 4.25 & 14 \\
\hline SWE25 & 7.6 & 78 & 3959 & 531 & 19.6 & - & 263.0 & 60 & 9.76 & 74 \\
\hline SWE25 & 8.7 & 70 & 3074 & 473.2 & 10.3 & 0.0366 & - & - & 5.62 & 29 \\
\hline SWE25 & 7 & 70 & 2580 & 577 & 4.7 & 0.043 & 103.0 & 12 & 3.53 & 5 \\
\hline SWE25 & 7.5 & 73 & 3160 & 580.6 & 3.4 & 0.0231 & 95.2 & 10 & 3.53 & 8 \\
\hline SWE26 & 6.0 & 83 & 4534 & 542.7 & 3.3 & - & 147.0 & 29 & 8.31 & 60 \\
\hline SWE26 & 7.6 & 77 & 3469 & 342.3 & 2 & 0.043 & - & - & 6.70 & 42 \\
\hline SWE26 & 6 & 81 & 3592 & 467.8 & 1.3 & 0.043 & 74.9 & 6 & 4.90 & 23 \\
\hline SWE26 & 6.8 & 82 & 4118 & 525.2 & 1.1 & 0.0278 & 81.1 & 7 & 6.05 & 34 \\
\hline
\end{tabular}


Table 2. Cont.

\begin{tabular}{|c|c|c|c|c|c|c|c|c|c|c|}
\hline \multirow{2}{*}{ Designation } & \multirow{2}{*}{$T,{ }^{\circ} \mathrm{C}$} & \multirow{2}{*}{$R H, \%$} & \multirow{2}{*}{$\begin{array}{c}\text { TOW, } \\
\text { Hours/a }\end{array}$} & \multirow{2}{*}{$\begin{array}{l}\text { Prec, } \\
\text { mm/a }\end{array}$} & \multirow{2}{*}{$\begin{array}{l}{\left[\mathrm{SO}_{2}\right],} \\
\mu \mathrm{g} / \mathrm{m}^{3}\end{array}$} & \multirow{2}{*}{$\begin{array}{l}{\left[\mathrm{H}^{+}\right]} \\
\mathrm{mg} / \mathrm{L}\end{array}$} & \multicolumn{2}{|c|}{ Steel } & \multicolumn{2}{|c|}{ Zinc } \\
\hline & & & & & & & $\mathrm{g} / \mathrm{m}^{2}$ & No. & $\mathrm{g} / \mathrm{m}^{2}$ & No. \\
\hline SPA31 & 14.1 & 66 & 2762 & 398 & 18.4 & - & 222.0 & 50 & 7.74 & 54 \\
\hline SPA31 & 15.2 & 56 & 1160 & 331.5 & 15.3 & 0.0073 & - & - & 4.82 & 22 \\
\hline SPA31 & 14.3 & 67 & 2319 & 360.1 & 8.2 & 0.0003 & 162.2 & 35 & 3.53 & 6 \\
\hline SPA31 & 15.7 & 68 & 2766 & 223.9 & 7.8 & 0.0002 & 151.3 & 32 & 2.30 & 2 \\
\hline SPA33 & 14.0 & 64 & 2275 & 785 & 3.3 & - & 45.0 & 3 & 3.37 & 3 \\
\hline SPA33 & 15.5 & 61 & 2147 & 610.4 & 13.5 & 0.0006 & - & - & 3.89 & 11 \\
\hline SPA33 & 13.4 & 61 & 1888 & 432.5 & 1.7 & 0.0012 & 25.7 & 1 & 3.89 & 10 \\
\hline SPA33 & 14.8 & 57 & 1465 & 327.4 & 4.2 & 0.0006 & 35.9 & 2 & 1.66 & 1 \\
\hline RUS34 & 5.5 & 73 & 2084 & 575.4 & 19.2 & - & 181.0 & 40 & 10.32 & 78 \\
\hline RUS34 & 5.7 & 76 & 2894 & 860.2 & 30.8 & 0.0006 & - & - & 8.64 & 64 \\
\hline RUS34 & 5.7 & 74 & 2444 & 880.6 & 28.7 & 0.0009 & 141.2 & 26 & 6.48 & 39 \\
\hline RUS34 & 5.6 & 71 & 1514 & 666.7 & 16.4 & 0.0008 & 120.9 & 19 & 4.61 & 17 \\
\hline EST35 & 5.5 & 83 & 4092 & 447.8 & 0.9 & - & 185.0 & 41 & 7.18 & 47 \\
\hline EST35 & 6.7 & 81 & 4332 & 532.7 & 0.6 & 0.0226 & - & - & 9.43 & 71 \\
\hline CAN37 & 5.5 & 75 & 3252 & 961.1 & 3.3 & - & 149.0 & 31 & 9.88 & 75 \\
\hline CAN37 & 5 & 79 & 3431 & 1103 & 3 & 0.042 & - & - & 6.26 & 38 \\
\hline CAN37 & 4.3 & 80 & 3302 & 1080 & 2.1 & 0.0482 & 110.0 & 16 & 5.26 & 27 \\
\hline CAN37 & 5.2 & 80 & 3386 & 1022.8 & 3.3 & 0.0461 & 103.7 & 14 & 6.19 & 36 \\
\hline US38 & 14.6 & 69 & 3178 & 846.7 & 9.6 & - & 176.0 & 38 & 10.72 & 82 \\
\hline US38 & 16.3 & 66 & 3026 & 1106.7 & 9.2 & 0.0358 & - & - & 12.46 & 90 \\
\hline US38 & 15.5 & 64 & 2644 & 982.3 & 10.1 & 0.0349 & 184.9 & 42 & 9.72 & 72 \\
\hline US38 & 15.8 & 68 & - & 1037.6 & 9.3 & 0.0482 & - & - & 4.75 & 21 \\
\hline US39 & 12.3 & 67 & 2111 & 733.1 & 58.1 & - & 214.0 & 49 & 13.61 & 91 \\
\hline US39 & 11.2 & 61 & 1391 & 967.4 & 55.2 & 0.0838 & - & - & 11.02 & 83 \\
\hline US39 & 11.8 & 65 & 1532 & 729.4 & 43.1 & 0.0941 & 290.2 & 67 & 7.34 & 50 \\
\hline US39 & 11.8 & 69 & - & 756.8 & 38.3 & 0.0765 & - & - & 5.26 & 28 \\
\hline
\end{tabular}


Table 3. Atmosphere corrosivity parameters of test locations, first-year corrosion losses of carbon steel and zinc $\left(K_{1}, \mathrm{~g} / \mathrm{m}^{2}\right)$ under the MICAT program and those reported in [20], and numbers of test locations in the order of increasing $K_{1}$. Adapted from [20], with permission from $\odot 2000$ Elsevier.

\begin{tabular}{|c|c|c|c|c|c|c|c|c|c|c|}
\hline \multirow{2}{*}{ Designation } & \multirow{2}{*}{$T,{ }^{\circ} \mathrm{C}$} & \multirow{2}{*}{$R H, \%$} & \multirow{2}{*}{ Rain, $\mathrm{mm} / \mathrm{a}$} & \multirow{2}{*}[\mathrm{SO}_{2}]{,$\mu \mathrm{g} / \mathrm{m}^{3}$} & \multirow{2}{*}{$\mathrm{Cl}^{-}, \mathrm{mg} /\left(\mathrm{m}^{2} \cdot\right.$ Day $)$} & \multirow{2}{*}{$T O W, \mathrm{~h} / \mathrm{a}$} & \multicolumn{2}{|c|}{ Steel } & \multicolumn{2}{|c|}{ Zinc } \\
\hline & & & & & & & $\mathrm{g} / \mathrm{m}^{2}$ & No. & $\mathrm{g} / \mathrm{m}^{2}$ & No. \\
\hline $\mathrm{A} 2 *$ & 16.7 & 75 & 1729 & 10 & Ins & 5063 & 122.5 & $36(34)$ & 8.06 & 41 \\
\hline $\mathrm{A} 2$ & 17.1 & 72 & 983 & 10 & Ins & 4222 & 125.6 & 38 & 7.56 & 39 \\
\hline A2 & 17.0 & 74 & 1420 & 9 & Ins & 4862 & 96.7 & 25 & 10.15 & 47 \\
\hline A3 & 20.6 & 76 & 2158 & Ins $(5) * *$ & Ins (1.5) & 5825 & 44.5 & $12(11)$ & 14.76 & 53 \\
\hline A3 & 20.9 & 74 & 2624 & Ins (5) & Ins (1.5) & 5528 & 45.2 & $13(12)$ & 8.42 & 43 \\
\hline A3 & 22.1 & 75 & 1720 & Ins (5) & Ins (1.5) & 5545 & 43.7 & $10(9)$ & 8.50 & 44 \\
\hline A4 & 18.0 & 51 & 35 & Ins (5) & Ins (1.5) & 999 & 35.9 & $6(6)$ & 2.02 & 15 \\
\hline A4 & 20.0 & 49 & 111 & Ins (5) & Ins (1.5) & 850 & 35.1 & $5(5)$ & 0.94 & 3 \\
\hline A4 & 18.3 & 51 & 93 & Ins (5) & Ins (1.5) & 867 & 43.7 & $11(10)$ & 1.58 & 10 \\
\hline A6 & 17.0 & 78 & 1178 & 6.22 & Ins & 5195 & 197.3 & $55(51)$ & 5.54 & 28 \\
\hline $\mathrm{A} 6^{*}$ & 16.7 & 77 & 1263 & 8.21 & Ins & 4949 & 224.6 & $59(55)$ & 6.70 & 32 \\
\hline $\mathrm{A} 6^{*}$ & 16.6 & 78 & 1361 & 6.2 & Ins & 5528 & 234.8 & $61(57)$ & 7.49 & 37 \\
\hline B1 & 21.2 & 75 & 996 & 1.67 & 1.57 & 4222 & 102.2 & $28(26)$ & 4.32 & 26 \\
\hline B6 & 19.7 & 75 & 1409 & $67.2(28)$ & Ins (1.5) & 5676 & 113.9 & $31(29)$ & 8.57 & 45 \\
\hline B6 & 19.5 & 76 & $1810(1910)$ & $66.8(28)$ & Ins (1.5) & 5676 & 182.5 & $53(49)$ & 10.66 & 48 \\
\hline B6 & 19.6 & 75 & 1034 & $48.8(28)$ & Ins (1.5) & 5676 & 188.8 & $54(50)$ & 6.98 & 34 \\
\hline B8 & 26.1 & 88 & 2395 & Ins (5) & Ins (1.5) & 5974 & 151.3 & $44(40)$ & 7.92 & 40 \\
\hline B10 & 20.4 & $69(72)$ & 1440 & Ins (5) & Ins (1.5) & 3872 & 100.6 & $26(24)$ & 12.82 & 50 \\
\hline B11 & 25.9 & 77 & 1392 & Ins & Ins & 1507 & 134.9 & 41 & 11.52 & 49 \\
\hline B12 & 26.6 & 90 & 2096 & Ins & Ins & 4222 & 38.2 & 8 & 23.83 & 57 \\
\hline $\mathrm{CO} 2$ & $9.6(14.1)$ & $98(81)$ & 1800 & $0.56(5)$ & Ins (1.5) & 8760 (7008) & 106.9 & $30(28)$ & 24.48 & 58 \\
\hline $\mathrm{CO} 2$ & 11.4 & 90 & 1800 & $0.56(5)$ & Ins (1.5) & $8760(7808)$ & 138.1 & $42(38)$ & 25.78 & 60 \\
\hline $\mathrm{CO} 2$ & $13.5(14.2)$ & $81(73)$ & 1800 & $0.56(5)$ & Ins (1.5) & $8760(7808)$ & 152.9 & $46(42)$ & 20.88 & 55 \\
\hline $\mathrm{CO} 3 *$ & 27.0 & 76 & 900 & 0.33 & Ins & 2891 & 120.9 & $35(33)$ & 18.65 & 54 \\
\hline $\mathrm{CO} 3 *$ & 27.0 & 76 & 900 & 0.33 & Ins & 2891 & 204.4 & 57 (53) & 27.00 & 61 \\
\hline $\mathrm{CO} 3 *$ & 27.0 & 76 & 900 & 0.33 & Ins & 2891 & 132.6 & $40(37)$ & 25.56 & 59 \\
\hline EC1 & 26.1 & 71 & 936 & 4.20 & 1.5 & 4853 & 152.1 & $45(41)$ & 1.08 & 5 \\
\hline EC1 & 26.9 & 82 & 635 & 2.72 & 1.31 & 5790 & 176.3 & $52(48)$ & 1.15 & 6 \\
\hline $\mathrm{EC} 1 *$ & 24.8 & 75 & 564 & 2.1 & 1.66 & 3101 & 201.2 & $56(52)$ & 2.38 & 17 \\
\hline EC2 & 12.9 & 66 & 554 & 1.0 & 0.4 & 3583 & 60.8 & $17(16)$ & - & - \\
\hline EC2* & 13.2 & 71 & 598 & 1.35 & 1.14 & 4932 & 70.2 & $21(20)$ & - & - \\
\hline
\end{tabular}


Table 3. Cont

\begin{tabular}{|c|c|c|c|c|c|c|c|c|c|c|}
\hline \multirow{2}{*}{ Designation } & \multirow{2}{*}{$T,{ }^{\circ} \mathrm{C}$} & \multirow{2}{*}{$R H, \%$} & \multirow{2}{*}{ Rain, mm/a } & \multirow{2}{*}[\mathrm{SO}_{2}]{,$\mu \mathrm{g} / \mathrm{m}^{3}$} & \multirow{2}{*}{$\mathrm{Cl}^{-}, \mathrm{mg} /\left(\mathrm{m}^{2} \cdot\right.$ Day $)$} & \multirow{2}{*}{ TOW, h/a } & \multicolumn{2}{|c|}{ Steel } & \multicolumn{2}{|c|}{ Zinc } \\
\hline & & & & & & & $\mathrm{g} / \mathrm{m}^{2}$ & No. & $\mathrm{g} / \mathrm{m}^{2}$ & No. \\
\hline E1 & 12.0 & 69 & 652 & $1.18(16.2)$ & 1.5 & 3364 & $158.3(150.5)$ & $48(44)$ & 3.02 & 20 \\
\hline $\mathrm{E} 1 *$ & 10.6 & 65 & 495 & 1.18 & 1.5 & 2374 & 175.5 & $51(47)$ & 2.88 & 18 \\
\hline E1 & 11.1 & 63 & 334 & $1.18(16.2)$ & 1.5 & 2111 & 153.7 & 47 (43) & 2.09 & 16 \\
\hline E4 & 18.1 & 65 & 554 & 8.3 & 1.5 & 3416 & 158.3 & $49(45)$ & 1.94 & 14 \\
\hline E4 & 17.0 & 63 & 521 & 5.7 & 1.5 & 2646 & 151.3 & $43(39)$ & 1.51 & 8 \\
\hline E4 & 17.2 & 62 & 374 & 1.9 & 1.5 & 2768 & 163.8 & $50(46)$ & 1.94 & 13 \\
\hline E5 & 16.3 & 59 & 416 & 10.3 & 1.5 & 1323 & 95.9 & $24(23)$ & 1.01 & 4 \\
\hline E5 & $15.0(15.8)$ & $59(58)$ & $258(239)$ & 5.4 & 1.5 & 1104 & 53.0 & 16 (15) & 0.65 & 2 \\
\hline E5 & 15.6 & 58 & 266 & 2.8 & 1.5 & 2400 & 49.9 & 15 (14) & 0.65 & 1 \\
\hline E8 & 8.8 & $52(72)$ & 738 & 9.1 & 1.8 & 876 & 25.7 & $3(3)$ & 1.66 & 11 \\
\hline E8 & 6.9 & $52(72)$ & 624 & 8.9 & 1.6 & 876 & 28.1 & $4(4)$ & 1.22 & 7 \\
\hline E8 & 7.8 & $52(72)$ & 681 & 9.0 & 1.7 & 876 & 37.4 & 7 (7) & 3.10 & 21 \\
\hline M1 & 16.0 & 62 & 743 & 15.6 & 1.5 & $2523(2321)$ & 120.1 & $34(32)$ & 5.83 & 29 \\
\hline M1 & 14.8 (15.2) & $66(65)$ & 747 & $7.7(5.6)$ & 1.5 & 2523 & 67.1 & 20 (19) & 5.98 & 31 \\
\hline M1 & 15.4 & $64(63)$ & 747 & 17.5 & 1.5 & $2523(2427)$ & 39.8 & $9(8)$ & 5.83 & 30 \\
\hline M2 & 21.0 & 56 & 1352 & 6.7 & 1.5 & 1664 & 118.6 & $33(31)$ & 8.35 & 42 \\
\hline M2 & 21.0 & 56 & 1724 & 9.9 & Ins (1.5) & 1857 & 88.9 & $22(21)$ & 14.33 & 52 \\
\hline M2 & 21.0 & 56 & 1372 & 7.1 & Ins (1.5) & 1752 & 106.9 & $29(27)$ & 6.84 & 33 \\
\hline M3 & 18.0 & 51 & 374 & 31.1 & Ins & 1410 & 292.5 & $62(58)$ & 10.01 & 46 \\
\hline M3* & 18.0 & 62 & 374 & 10.9 & Ins & 1410 & 205.9 & $58(54)$ & 21.24 & 56 \\
\hline M3* & 18.0 & 60 & 374 & 14.6 & Ins & 2646 & 229.3 & $60(56)$ & 7.06 & 35 \\
\hline PE4 & 16.4 & 37 & 17 & Ins (5) & Ins (1.5) & 26 & 117.0 & $32(30)$ & 1.66 & 12 \\
\hline PE4 & 17.2 & 33 & $34(89)$ & Ins (5) & Ins (1.5) & $175(26)$ & 128.7 & $39(36)$ & 1.58 & 9 \\
\hline PE5 & 12.2 & 67 & 632 & Ins (0) & Ins (0) & 2847 & 7.8 & $1(1)$ & 3.89 & 23 \\
\hline PE5 & 12.2 & 67 & $672(792)$ & Ins (0) & Ins (0) & $2689(2847)$ & 13.3 & $2(2)$ & 2.88 & 19 \\
\hline PE6 & 25.4 & 84 & 1523 & Ins (5) & Ins (1.5) & $5037(4580)$ & 122.5 & 37 (35) & 7.06 & 36 \\
\hline PE6 & 25.8 & 83 & $1158(1656)$ & Ins (5) & Ins (1.5) & $5790(4380)$ & 100.6 & $27(25)$ & 7.49 & 38 \\
\hline U1 & 16.8 & 74 & 1182 & $0.6(1)$ & $1.8(2.2)$ & 5133 & 64.0 & 19 (18) & 4.03 & 24 \\
\hline U1 * & 16.6 & 73 & 1324 & 0.8 & 1.2 & 4976 & 62.4 & 18 (17) & 3.74 & 22 \\
\hline U1 * & 16.7 & 76 & 1306 & Ins & Ins & 4792 & 47.6 & 14 (13) & 4.10 & 25 \\
\hline U3 * & 17.7 & 79 & 1490 & Ins & Ins & 5764 & 94.4 & $23(22)$ & 4.39 & 27 \\
\hline $\mathrm{CH} 1$ & 14.2 & 71 & 355 & 20 & 2.18 & 3469 & 221.5 & 63 & 12.89 & 51 \\
\hline
\end{tabular}

${ }^{*}$ the test locations not used in [20]; ** the values reported in [20] are shown in parentheses. 
Table 4. Atmosphere corrosivity parameters of test locations and first-year corrosion losses of carbon steel and zinc $\left(K_{1}, \mathrm{~g} / \mathrm{m}^{2}\right)$ in Russian Federation test locations and their numbers in the order of increasing $K_{1}$.

\begin{tabular}{|c|c|c|c|c|c|c|c|c|}
\hline \multirow{2}{*}{ Test Location } & \multirow{2}{*}{$T,{ }^{\circ} \mathrm{C}$} & \multirow{2}{*}{$R H, \%$} & \multirow{2}{*}{ Prec, $\mathrm{mm} / \mathrm{a}$} & \multirow{2}{*}[\mathrm{SO}_{2}]{,$\mu \mathrm{g} / \mathrm{m}^{3}$} & \multicolumn{2}{|c|}{ Steel } & \multicolumn{2}{|c|}{ Zinc } \\
\hline & & & & & $\mathrm{g} / \mathrm{m}^{2}$ & No. & $\mathrm{g} / \mathrm{m}^{2}$ & No. \\
\hline Bilibino & -12.2 & 80 & 218 & 3 & 5.4 & 1 & 1.64 & 1 \\
\hline Oimyakon & -16.6 & 71 & 175 & 3 & 8.1 & 2 & 1.81 & 3 \\
\hline Ust-Omchug & -11 & 70 & 317 & 5 & 12.4 & 3 & 2.91 & 5 \\
\hline Atka & -12 & 72 & 376 & 3 & 15.2 & 4 & 1.69 & 2 \\
\hline Susuman & -13.2 & 71 & 283 & 10 & 17.0 & 5 & 3.07 & 6 \\
\hline Tynda & -6.5 & 72 & 525 & 5 & 21.2 & 6 & 5.30 & 10 \\
\hline Klyuchi & 1.4 & 69 & 253 & 3 & 23.4 & 7 & 2.03 & 4 \\
\hline Aldan & -6.2 & 72 & 546 & 5 & 24.6 & 8 & 5.47 & 11 \\
\hline Pobedino & -0.9 & 77 & 604 & 3 & 36.5 & 9 & 4.30 & 7 \\
\hline Yakovlevka & 2.5 & 70 & 626 & 3 & 40.6 & 10 & 4.64 & 9 \\
\hline Pogranichnyi & 3.6 & 67 & 595 & 3 & 49.0 & 11 & 4.32 & 8 \\
\hline Komsomolsk-on-Amur & -0.7 & 76 & 499 & 10 & 63.2 & 12 & 6.35 & 12 \\
\hline
\end{tabular}

Table 5. Atmosphere corrosivity parameters and first-year corrosion losses of carbon steel in test locations. Adapted from [19], with permission from (C) 1999 Elsevier.

\begin{tabular}{ccc}
\hline$\left[\mathrm{SO}_{2}\right], \mu \mathrm{g} / \mathbf{m}^{3}$ & $\mathrm{Cl}^{-}, \mathbf{m g} /\left(\mathbf{m}^{2} \cdot\right.$ Day $)$ & $\boldsymbol{K}_{\mathbf{1}}, \mathbf{g} / \mathbf{m}^{2}$ \\
\hline 3 & 2 & 137.7 \\
5 & 0,3 & 46.1 \\
5 & 0,7 & 130.7 \\
8 & 1 & 137.7 \\
8 & 0 & 140.0 \\
14 & 2 & 193.8 \\
15 & 2 & 228.4 \\
15 & 1 & 236.1 \\
17 & 0,16 & 136.1 \\
26 & 1 & 236.1 \\
32 & 2 & 276.1 \\
116 & 0,62 & 232.2 \\
\hline
\end{tabular}

\subsection{Predictions of First-Year Corrosion Losses}

To predict $K_{1}$ for steel and zinc, we used the new DRFs presented in this paper (hereinafter referred to as "New DRFs"), in the standard [18] (hereinafter referred to as "Standard DRFs"), in [13] (hereinafter referred to as "Unified DRFs"), and the linear model [20] (hereinafter referred to as "Linear DRF").

The Standard DRFs are intended for the prediction of $K_{1}\left(r_{\text {corr }}\right.$ in the original) in $\mathrm{SO}_{2}$ - and $\mathrm{Cl}^{-}$-containing atmospheres in all climatic regions of the world. The $K_{1}$ values are calculated in $\mu \mathrm{m}$.

For carbon steel, Equation (3):

$$
K_{1}=1.77 \times P_{\mathrm{d}}^{0.52} \times \exp \left(0.020 \times R H+f_{\mathrm{St}}\right)+0.102 \times S_{\mathrm{d}}{ }^{0.62} \times \exp (0.033 \times R H+0.040 \times T),
$$

where $f_{\mathrm{St}}=0.150 \cdot(T-10)$ at $T \leq 10^{\circ} \mathrm{C} ; f_{\mathrm{St}}=-0.054 \cdot(T-10)$ at $T>10^{\circ} \mathrm{C}$.

For zinc, Equation (4):

$$
K_{1}=0.0129 \times P_{\mathrm{d}}^{0.44} \times \exp \left(0.046 \times R H+f_{\mathrm{Zn}}\right)+0.0175 \times S_{\mathrm{d}}{ }^{0.57} \times \exp (0.008 \times R H+0.085 \times T),
$$

where $f_{\mathrm{Zn}}=0.038 \times(T-10)$ at $T \leq 10{ }^{\circ} \mathrm{C} ; f_{\mathrm{Zn}}=-0.071 \times(T-10)$ at $T>10{ }^{\circ} \mathrm{C}$, where $T$ is the temperature $\left({ }^{\circ} \mathrm{C}\right)$ and $R H(\%)$ is the relative humidity of air; $P_{\mathrm{d}}$ and $S_{\mathrm{d}}$ are $\mathrm{SO}_{2}$ and $\mathrm{Cl}^{-}$deposition rates expressed in $\mathrm{mg} /\left(\mathrm{m}^{2}\right.$ day $)$, respectively.

In Equations (3) and (4), the contributions to corrosion due to $\mathrm{SO}_{2}$ and $\mathrm{Cl}^{-}$are presented as separate components; therefore, only their first components were used for continental territories. 
Unified DRFs are intended for long-term prediction of mass losses $K$ (designated as $M L$ in the original) in $\mathrm{SO}_{2}$-containing atmospheres in all climatic regions of the Earth. It is stated that the calculation is given in $\mathrm{g} / \mathrm{m}^{2}$.

For carbon steel, Equation (5):

$$
\begin{aligned}
& K=3.54 \times\left[\mathrm{SO}_{2}\right]^{0.13} \times \exp \{0.020 \times R H+0.059 \times(T-10)\} \times \tau^{0.33} \mathrm{~T} \leq 10^{\circ} \mathrm{C} \\
& K=3.54 \times\left[\mathrm{SO}_{2}\right]^{0.13} \times \exp \{0.020 \times R H-0.036 \times(T-10)\} \times \tau^{0.33} \mathrm{~T}>10^{\circ} \mathrm{C} .
\end{aligned}
$$

For zinc, Equation (6):

$$
\begin{aligned}
& K=1.35 \times\left[\mathrm{SO}_{2}\right]^{0.22} \times \exp \{0.018 \times R H+0.062 \times(T-10)\} \times \tau^{0.85}+0.029 \times \operatorname{Rain}\left[\mathrm{H}^{+}\right] \times \tau \mathrm{T} \leq 10^{\circ} \mathrm{C} ; \\
& K=1.35 \times\left[\mathrm{SO}_{2}\right]^{0.22} \times \exp \{0.018 \times R H-0.021 \times(T-10)\} \times \tau^{0.85}+0.029 \times \operatorname{Rain}\left[\mathrm{H}^{+}\right] \times \tau T>10^{\circ} \mathrm{C} .
\end{aligned}
$$

where $\mathrm{T}$ is the temperature $\left({ }^{\circ} \mathrm{C}\right)$ and $\mathrm{RH}(\%)$ is the relative humidity of air; $\left[\mathrm{SO}_{2}\right]$ is the concentration of $\mathrm{SO}_{2}$ in $\mu \mathrm{g} / \mathrm{m}^{3}$; "Rain" is the rainfall amount in $\mathrm{mm} /$ year; $\left[\mathrm{H}^{+}\right]$is the acidity of the precipitation; and $\tau$ is the exposure time in years.

To predict the first-year corrosion losses, $\tau=1$ was assumed.

The standard DRFs and Unified DRFs were developed on the basis of the results obtained in the UN/ECE program and MICAT project using the same atmosphere corrosivity parameters (except from Rain $\left.\left[\mathrm{H}^{+}\right]\right)$. If $\tau=1$, the models have the same mathematical form and only differ in the coefficients. Both models are intended for $K_{1}$ predictions in any regions of the world, hence it is particularly interesting to compare the results of $K_{1}$ predictions with actual data.

The linear model was developed for $\mathrm{SO}_{2^{-}}$and $\mathrm{Cl}^{-}$-containing atmospheres. It is based on the experimental data from the MICAT project only and relies on an artificial neural network. It is of special interest since it has quite a different mathematical form and uses different parameters. In the MICAT project, the air temperature at the test sites is mainly above $10^{\circ} \mathrm{C}$ (Table 3 ). Nevertheless, we used this model, like the other DRFs, also for test locations with any temperatures.

The first-year corrosion losses of carbon steel (designated as "Fe" in the original) are expressed as Equation (7):

$$
K_{1}=b_{0}+\mathrm{Cl}^{-} \times\left(\mathrm{b}_{1}+\mathrm{b}_{2} \times \mathrm{P}+\mathrm{b}_{3} \times R H\right)+\mathrm{b}_{4} \times \mathrm{TOW} \times\left[\mathrm{SO}_{2}\right],
$$

where $b_{0}=6.8124, b_{1}=-1.6907, b_{2}=0.0004, b_{3}=0.0242$, and $b_{4}=2.2817 ; K_{1}$ is the first-year corrosion loss in $\mu \mathrm{m} ; \mathrm{Cl}^{-}$is the chloride deposition rate in $\mathrm{mg} /\left(\mathrm{m}^{2} \cdot\right.$ day); $\mathrm{P}$ is the amount of precipitation in $\mathrm{mm}$ /year; $\mathrm{RH}$ is the air relative humidity in \%; TOW is the wetting duration expressed as the fraction of a year; and $\left[\mathrm{SO}_{2}\right]$ is the $\mathrm{SO}_{2}$ concentration in $\mu \mathrm{g} / \mathrm{m}^{3}$. The prediction results for the first year are expressed in $\mu \mathrm{m}$.

To predict $K_{1}$ in continental regions, only the component responsible for the contribution to corrosion due to $\mathrm{SO}_{2}$ was used.

The $K_{1}$ values in $\mu \mathrm{m}$ were converted to $\mathrm{g} / \mathrm{m}^{2}$ using the specific densities of steel and zinc, 7.8 and $7.2 \mathrm{~g} / \mathrm{cm}^{3}$, respectively. Furthermore, the relationship $P_{\mathrm{d}, \mathrm{p}} \mathrm{mg} /\left(\mathrm{m}^{2} \cdot\right.$ day $)=0.67 P_{\mathrm{d}, \mathrm{c}} \mu \mathrm{g} / \mathrm{m}^{3}$ was used, where $P_{\mathrm{d}, \mathrm{p}}$ is the $\mathrm{SO}_{2}$ deposition rate and $P_{\mathrm{d}, \mathrm{c}}$ is the $\mathrm{SO}_{2}$ concentration [18].

The calculation of $K_{1}$ is given for continental test locations at background $\mathrm{Cl}^{-}$deposition rates $\leq 2$ $\mathrm{mg} /\left(\mathrm{m}^{2}\right.$-day) under UN/ECE and RF programs and MICAT project. The $\mathrm{R}^{2}$ values characterizing the prediction results as a whole for numerous test locations are not reported here. The $K_{1}$ predictions obtained were compared to the experimental values of $K_{1}$ for each test location, which provides a clear idea about the specific features of the DRFs.

\section{Results}

\subsection{DRF Development}

Corrosion of metals in continental regions depends considerably on the content of sulfur dioxide in the air. Therefore, development of a DRF primarily requires that this dependence, i.e., the mathematical 
relationship $K=f\left(\mathrm{SO}_{2}\right)$, be found. The dependences reported in graphical form in [20,27] differ from each other. The relationship is non-linear, therefore the decision should be made on which background $\mathrm{SO}_{2}$ concentration should be selected, since the calculated $K_{1}$ values would be smaller than the experimental ones at $\left[\mathrm{SO}_{2}\right]<1$ if non-linear functions are used. $\left[\mathrm{SO}_{2}\right]$ values $<1$ can only be used in linear functions. The background values in Tables $2-4$ are presented as "Ins." (Insignificant), $\leq 1,3$, $5 \mu \mathrm{g} / \mathrm{m}^{3}$, which indicates that there is no common technique in the determination of background concentrations. For $\mathrm{SO}_{2}$ concentrations of "Ins." or $\leq 1 \mu \mathrm{g} / \mathrm{m}^{3}$, we used the value of $1 \mu \mathrm{g} / \mathrm{m}^{3}$, whereas the remaining $\mathrm{SO}_{2}$ concentrations were taken from the tables.

In finding the $K=f\left(\mathrm{SO}_{2}\right)$ relationship, we used the actual test results of all first-year exposures under each program rather than the mean values, because non-linear functions are also used.

The $K=f\left(\mathrm{SO}_{2}\right)$ relationships obtained for each program are shown in Figure 1 for steel and in Figure 2 for zinc. In a first approximation, this relationship can be described by the following function for experimental $K_{1}$ values obtained in a broad range of meteorological atmosphere parameters:

$$
K_{1}=K_{1}^{\circ} \times\left[\mathrm{SO}_{2}\right]^{\alpha},
$$

where $K_{1}{ }^{\circ}$ are the average corrosion losses over the first year $\left(\mathrm{g} / \mathrm{m}^{2}\right)$ in a clean atmosphere for the entire range of $T$ and $R H$ values; and $\alpha$ is the exponent that depends on the metal.

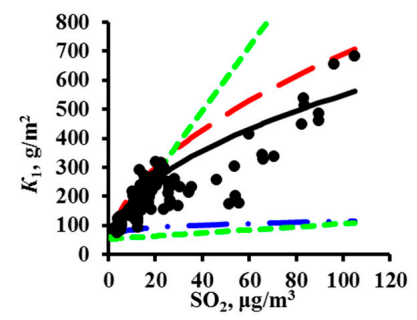

(a)

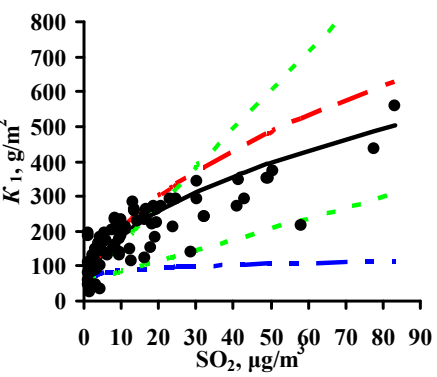

(c)

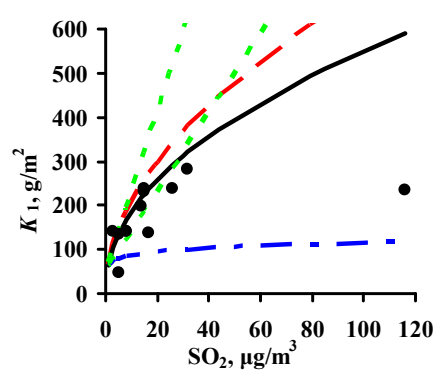

(b)

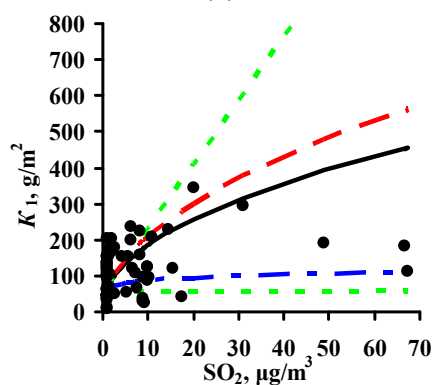

(d)

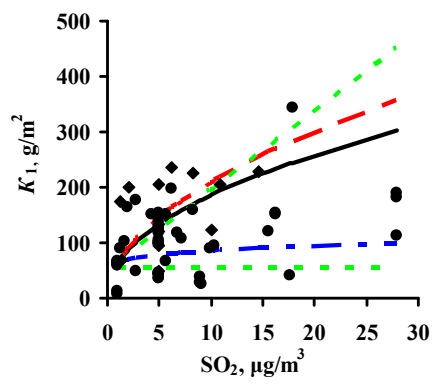

(e)

Figure 1. Dependence of first-year corrosion losses of steel $\left(K_{1}\right)$ on $\mathrm{SO}_{2}$ concentration based on data from ISO CORRAG program (a), Ref. [19] (b), UN/ECE program (c), MICAT project (d), and data from MICAT project cited in [20] (e). - - $\alpha=0.47$ (New DRF), - - $\alpha=0.52$ (Standard DRF), $-\bullet-— \alpha=0.13$ (Unified DRF), ---_model [20] for TOW ranges in accordance with the data in Tables 2-5. 


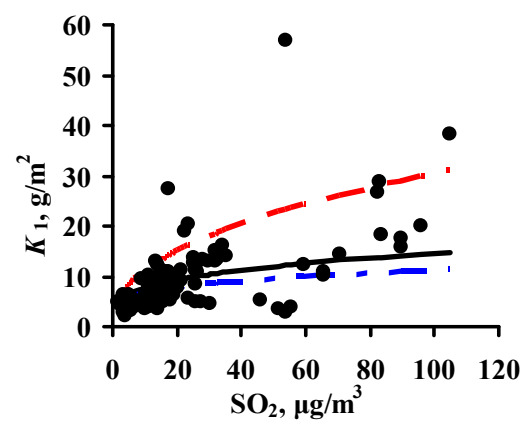

(a)

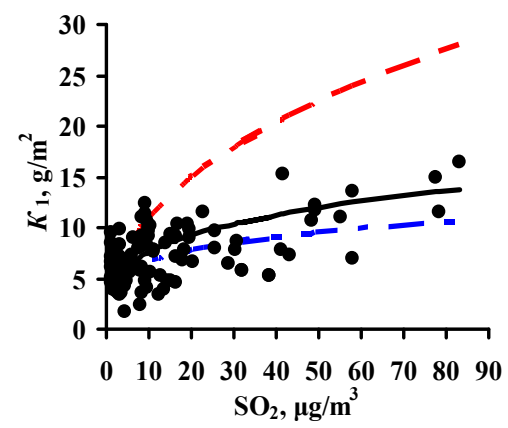

(b)

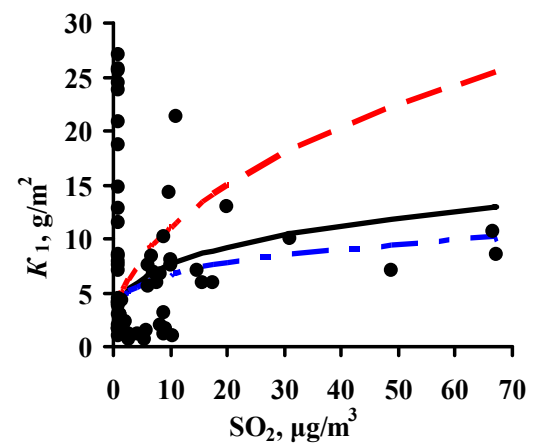

(c)

Figure 2. Dependence of first-year corrosion losses of zinc $\left(K_{1}\right)$ on $\mathrm{SO}_{2}$ concentration based on the data from ISO CORRAG program (a), UN/ECE program (b), and MICAT project (c). - - $-\alpha=0.28$ (New DRF), --— $\alpha=0.44$ (Standard DRF), -•-— $\alpha=0.22$ (Unified DRF).

The $K_{1}{ }^{\circ}$ values corresponding to the mean values of the parameter range of climatic conditions in clean atmospheres were found to be the same for the experimental data of all programs, namely, 63 and $4 \mathrm{~g} / \mathrm{m}^{2}$, while $\alpha=0.47$ and 0.28 for carbon steel and zinc, respectively. A similar $K_{1}{ }^{\circ}$ value for carbon steel was also obtained from the Linear DRF, Equation (6). In fact, at background $\mathrm{SO}_{2}$ concentrations $=1 \mu \mathrm{g} / \mathrm{m}^{3}$ in PE4 test location (Table 3) at TOW $=26 \mathrm{~h} /$ year $(0.002$ of the year), the calculated $K_{1}{ }^{\circ}$ is to $53 \mathrm{~g} / \mathrm{m}^{2}$, while for $\mathrm{CO}_{2}$ test location at TOW $=8760 \mathrm{~h} /$ year (entire year) it is $71 \mathrm{~g} / \mathrm{m}^{2}$; the mean value is $62 \mathrm{~g} / \mathrm{m}^{2}$.

Based on Equation (8), it may be accepted in a first approximation that the effect of $\left[\mathrm{SO}_{2}\right]$ on corrosion is the same under any climatic conditions and this can be expressed in a DRF by an $\left[\mathrm{SO}_{2}\right]^{\alpha}$ multiplier, where $\alpha=0.47$ or $\alpha=0.28$ for steel or zinc, respectively. The $K_{1}{ }^{\circ}$ values in Equation (8) depend on the climatic conditions and are determined for each test location based on the atmosphere meteorological parameters.

In the development of New DRF, the $K_{1}$ values were determined using the DRF mathematical formula presented in the Standard DRF and in the Unified DRF, as well as meteorological parameters $T, R H$, and Prec (Rain for warm climate locations or Prec for cold climate locations). The complex effect of $T$ was taken into account: corrosion losses increase with an increase in $T$ to a certain limit, $T_{\text {lim }}$; its further increase slows down the corrosion due to radiation heating of the surface of the material and accelerated evaporation of the adsorbed moisture film [12,28]. It has been shown [29] that $T_{\lim }$ is within the range of $9-11^{\circ} \mathrm{C}$. Similarly to Equations (3)-(6), it is accepted that $T_{\text {lim }}$ equals $10{ }^{\circ} \mathrm{C}$. The need to introduce Prec is due to the fact that in northern RF regions, the $K_{1}$ values are low at high $R H$, apparently owing not only to low $T$ values but also to the small amount of precipitation, including solid precipitations. The values of the coefficients reflecting the effect of $T, R H$ and Prec on corrosion were determined by regression analysis.

The New DRFs developed for the prediction of $K_{1}\left(\mathrm{~g} / \mathrm{m}^{2}\right)$ for the two temperature ranges have the following forms: 
for carbon steel:

$$
\begin{aligned}
& K_{1}=7.7 \times\left[\mathrm{SO}_{2}\right]^{0.47} \times \exp \{0.024 \times R H+0.095 \times(T-10)+0.00056 \times \text { Prec }\} \mathrm{T} \leq 10^{\circ} \mathrm{C} ; \\
& K_{1}=7.7 \times\left[\mathrm{SO}_{2}\right]^{0.47} \times \exp \{0.024 \times R H-0.095 \times(T-10)+0.00056 \times \text { Prec }\}>10^{\circ} \mathrm{C} \text {, }
\end{aligned}
$$

and for zinc:

$$
\begin{aligned}
& K_{1}=0.71 \times\left[\mathrm{SO}_{2}\right]^{0.28} \times \exp \{0.022 \times R H+0.045 \times(T-10)+0.0001 \times \text { Prec }\} \leq 10^{\circ} \mathrm{C} ; \\
& K_{1}=0.71 \times\left[\mathrm{SO}_{2}\right]^{0.28} \times \exp \{0.022 \times R H-0.085 \times(T-10)+0.0001 \times \text { Prec }\} T>10^{\circ} \mathrm{C} .
\end{aligned}
$$

\subsection{Predictions of $K_{1}$ Using Various DRFs for Carbon Steel}

Predictions of $K_{1}$ were performed for all continental test locations with chloride deposition rates $\leq 2 \mathrm{mg} /\left(\mathrm{m}^{2}\right.$.day). The results of $K_{1}$ prediction $\left(K_{1}{ }^{\mathrm{pr}}\right)$ from Equations (3)-(7), (9), and (10) are presented separately for each test program. To build the plots, the test locations were arranged by increasing experimental $K_{1}$ values $\left(K_{1}{ }^{\text {exp }}\right)$. Their sequence numbers are given in Tables $2-4$. The increase in $K_{1}$ is caused by an increase in atmosphere corrosivity due to meteorological parameters and $\mathrm{SO}_{2}$ concentration. All the plots are drawn on the same scale. All plots show the lines of prediction errors $\delta= \pm 30 \%$ (the $1.3 K_{1}{ }^{\exp }-0.7 K_{1}{ }^{\exp }$ range). This provides a visual idea of the comparability of $K_{1}{ }^{p r}$ with $K_{1}{ }^{\exp }$ for each DRF. The scope of this paper does not include an estimation of the discrepancy between the $K_{1}{ }^{\mathrm{pr}}$ values obtained using various DRFs with the $K_{1}{ }^{\exp }$ values obtained for each test location under the UN/ECE and RF programs. The scatter of points is inevitable. It results from the imperfection of each DRF and the inaccuracy of experimental data on meteorological parameters, $\mathrm{SO}_{2}$ content, and $K_{1}{ }^{\exp }$ values. Let us just note the general regularities of the results on $K_{1}{ }^{\text {pr }}$ for each DRF.

The results on $K_{1}{ }^{\mathrm{pr}}$ for carbon steel for the UN/ECE program, MICAT project, and RF program are presented in Figures 3-5, respectively. It should be noted that according to the Unified DRF (Equation (5)), the $K_{1}{ }^{\mathrm{pr}}$ of carbon steel in RF territory [30] had low values. It was also found that the $K_{1}{ }^{p r}$ values are very low for the programs mentioned above. Apparently, the $K_{1}{ }^{p r}$ values (Equation (5)) were calculated in $\mu \mathrm{m}$ rather than in $\mathrm{g} / \mathrm{m}^{2}$, as the authors assumed. To convert $K_{1} \mathrm{pr}^{\mathrm{r}} \mu \mathrm{m}$ to $K_{1} \mathrm{pr}$ in $\mathrm{g} / \mathrm{m}^{2}$, the 3.54 coefficient in Equation (6) was increased 7.8-fold.

In the UN/ECE program, the $K_{1}{ }^{p r}$ values match $K_{1}{ }^{\exp }$ to various degrees; some $K_{1}{ }^{\mathrm{pr}}$ values exceed the error $\delta$ (Figure 3). Let us describe in general the locations in which $K_{1}$ pr values exceed $\delta$. For the New DRFs (Figure 3a) there are a number of locations with overestimated $K_{1} \mathrm{pr}$ and with underestimated $K_{1}{ }^{\mathrm{pr}}$ values at different atmosphere corrosivities. For the Standard DRF (Figure $3 b$ ) and Linear DRF (Figure 3d), locations with underestimated $K_{1}{ }^{\mathrm{pr}}$ values prevail, also at different $K_{1}{ }^{\text {exp}}$. For the Unified DRF (Figure $3 c$ ), $K_{1}{ }^{p r}$ are overestimated for locations with small $K_{1}{ }^{\exp }$ and underestimated for locations with high $K_{1}{ }^{\exp }$. The possible reasons for such regular differences for $K_{1}{ }^{\mathrm{pr}}$ from $K_{1}{ }^{\exp }$ will be given based on an analysis of the coefficients in the DRFs.

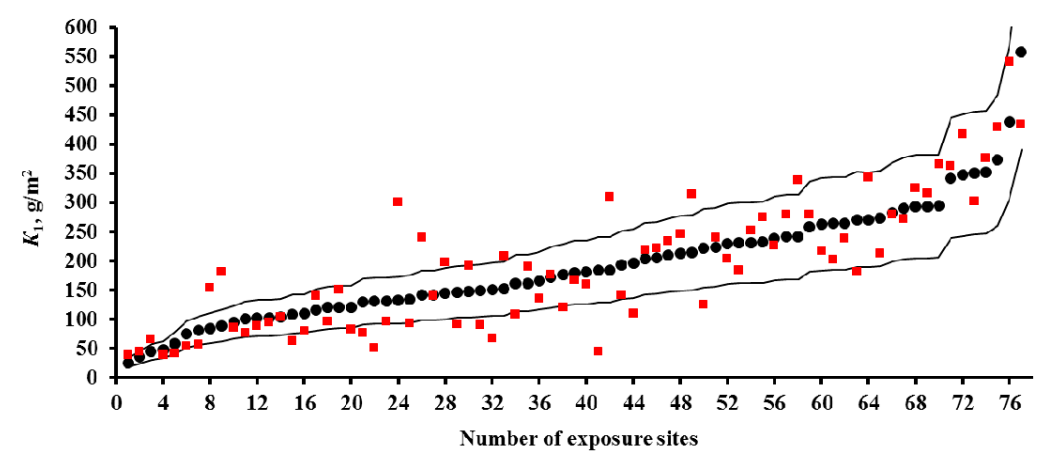

(a)

Figure 3. Cont. 


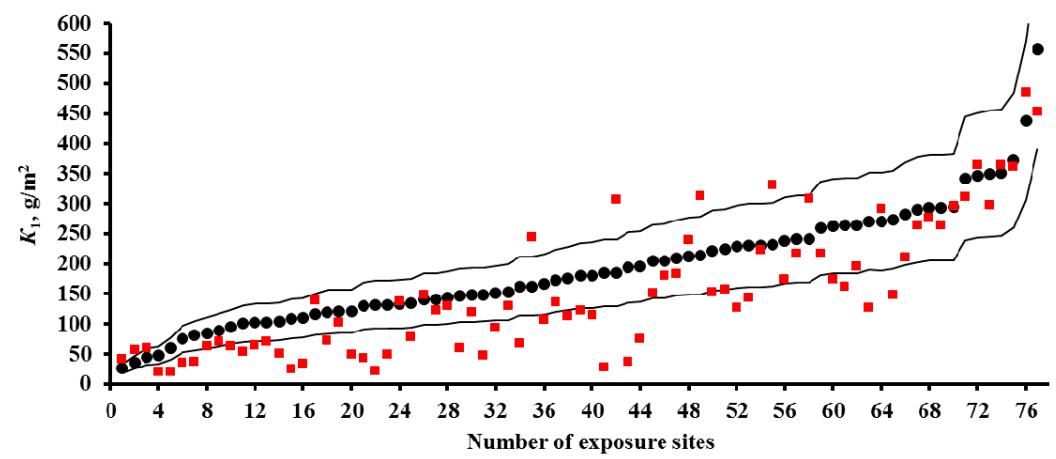

(b)

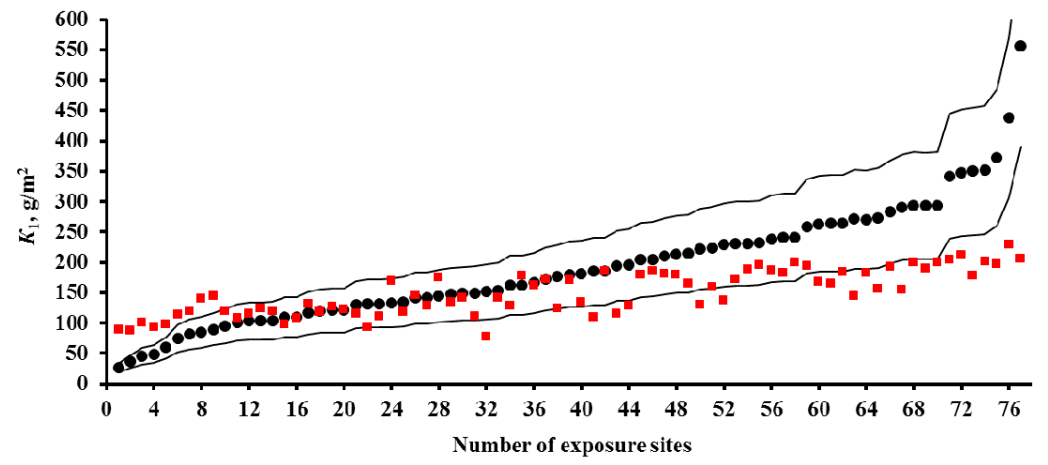

(c)

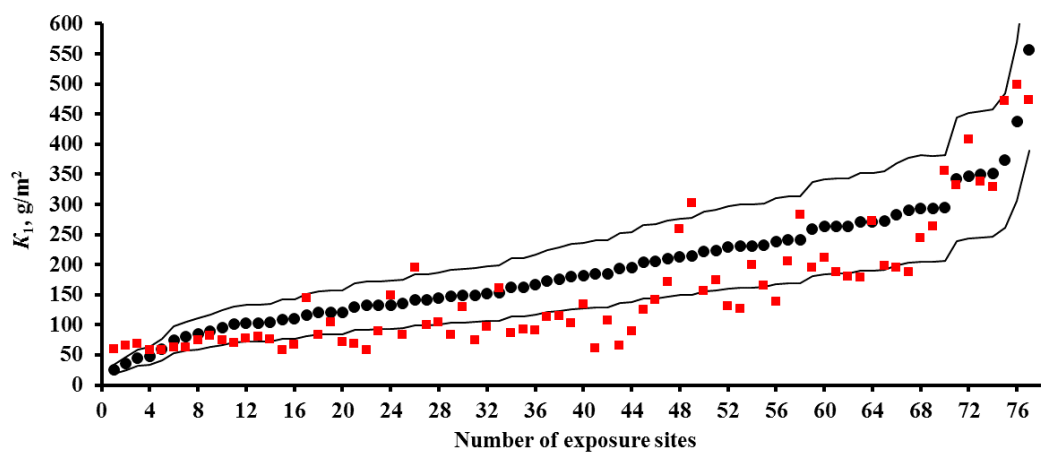

(d)

Figure 3. Carbon steel. UN/ECE program. $K_{1}$ predictions by the New DRF (a); Standard DRF (b); Unified DRF (c); and Linear DRF [20] (d). - - experimental $K_{1}$ data; $\square-K_{1}$ predictions. Thin lines show the calculation error $( \pm 30 \%)$. The numbers of the exposure sites are given in accordance with Table 2.

For the MICAT project, $K_{1}{ }^{p r}$ considerably exceeds $\delta$ for all DRFs in many locations (Figure 4 ). Overestimated and considerably overestimated $K_{1} \mathrm{pr}$ values are mainly observed in locations with small $K_{1}{ }^{\text {exp }}$, while underestimated $K_{1}{ }^{p r}$ values are mainly observed for locations with high $K_{1}{ }^{\exp }$. Furthermore, for the Linear DRF (Figure $4 \mathrm{~d}$ ), particularly overestimated values are observed in location B6 (No. 31, No. 53, and No. 54) at all exposures. This test location should be noted. The corrosivity parameters under this program reported in [20] are different for some test locations (Table 3). In fact, for $\mathrm{B} 6$, the $\left[\mathrm{SO}_{2}\right]$ value for all exposures is reported to be $28 \mu \mathrm{g} / \mathrm{m}^{3}$ instead of $67.2 ; 66.8$ and $48.8 \mu \mathrm{g} / \mathrm{m}^{3}$. Figure $4 \mathrm{e}$ presents $K_{1}{ }^{\mathrm{pr}}$ for the Linear DRF with consideration for the parameter values reported in [20]. Naturally, $K_{1} \mathrm{pr}$ for $\mathrm{B} 6$ decreased considerably in comparison with the values in Figure $4 \mathrm{~d}$ but remained rather overestimated with respect to $K_{1}{ }^{\exp }$. 


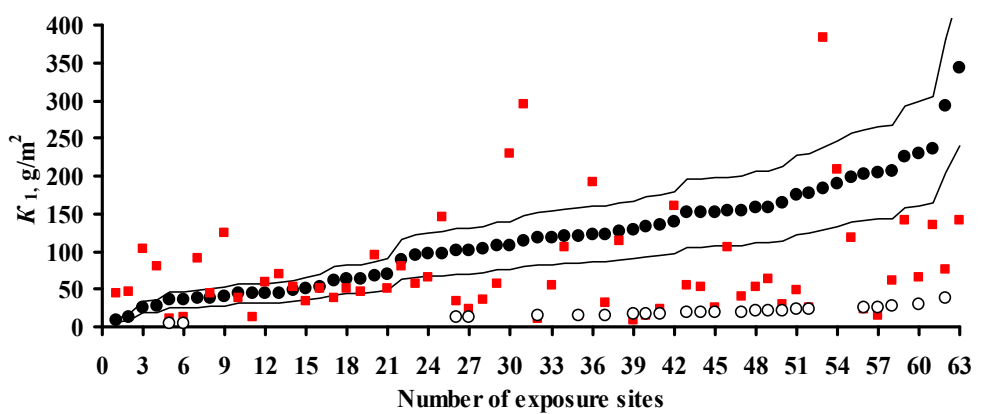

(a)

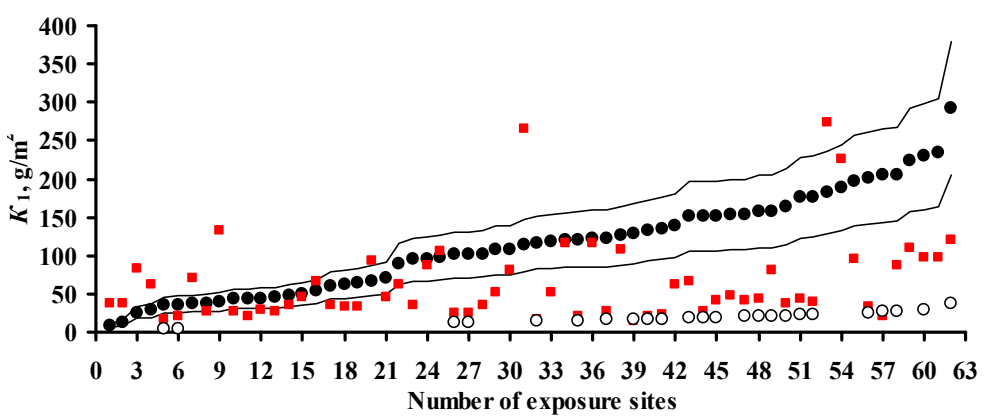

(b)

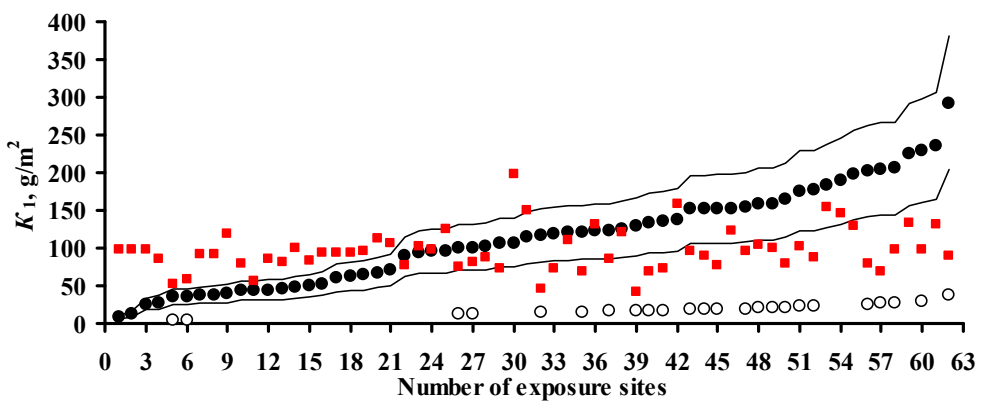

(c)

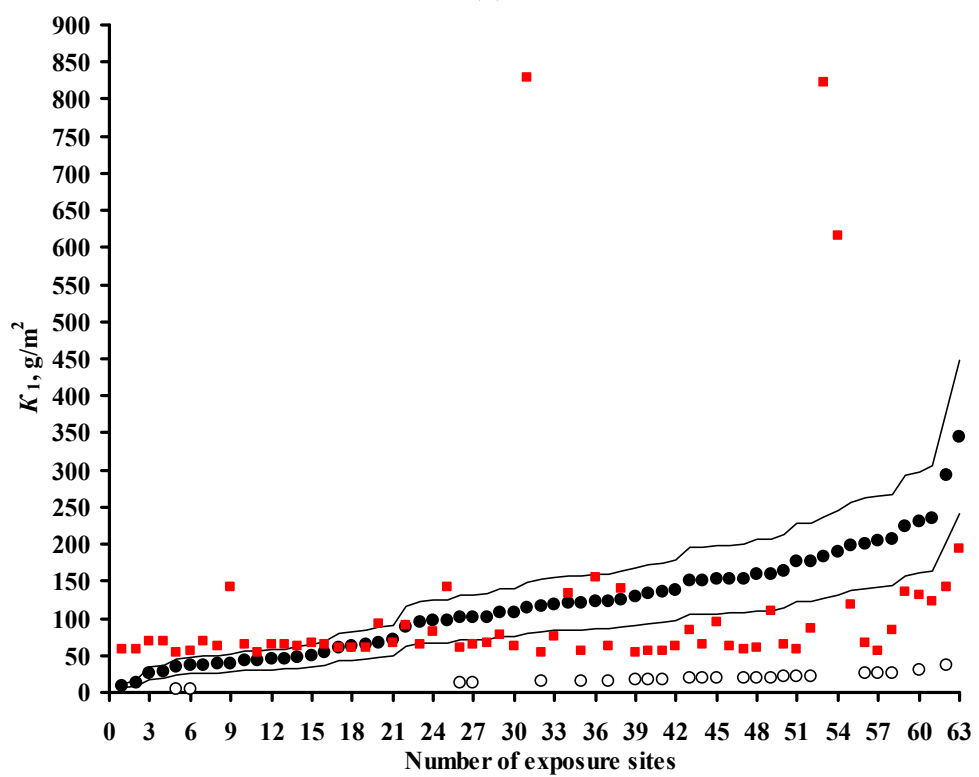

(d)

Figure 4. Cont. 


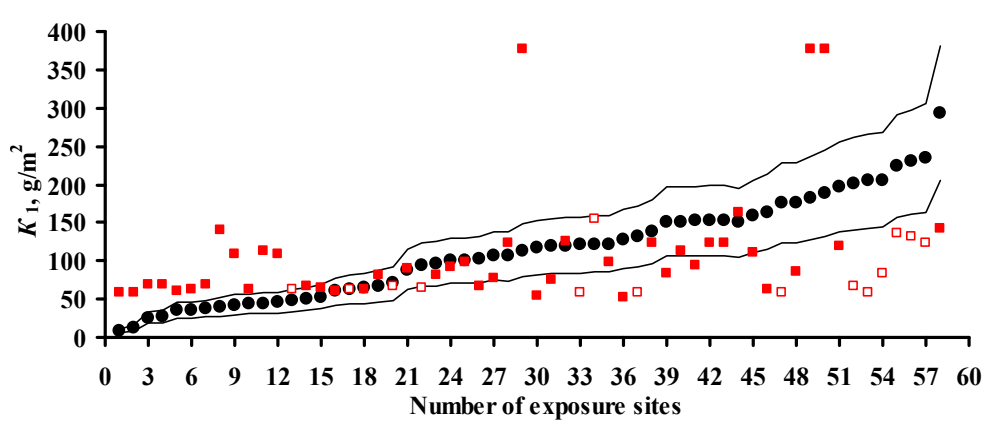

(e)

Figure 4. Carbon steel. MICAT program. $K_{1}$ predictions by the New DRF (a); Standard DRF (b); Unified DRF (c); linear model [20] (d); and linear model based on data from [20] (e). • - experimental $K_{1}$ data; $\square-K_{1}$ predictions; $\square$ - the test locations in [20] which were not used (only for Figure 4e); $\bigcirc$-experimental $K_{1}$ data under the assumption that they were expressed in $\mathrm{g} / \mathrm{m}^{2}$ rather than in $\mu \mathrm{m}$. Thin lines show the calculation error $( \pm 30 \%)$. The numbers of the exposure sites are given in accordance with Table 3.

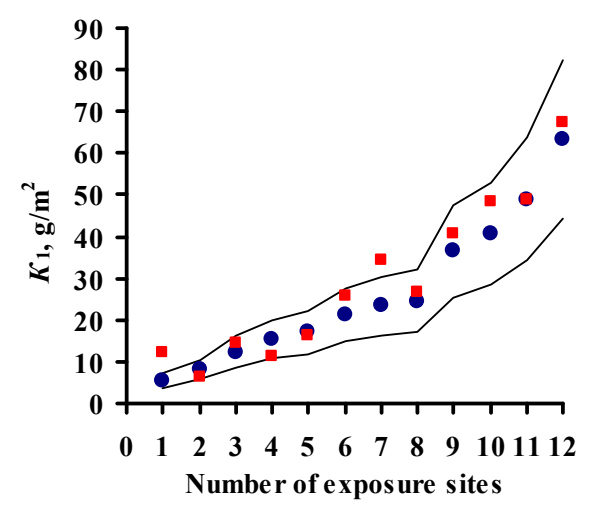

(a)

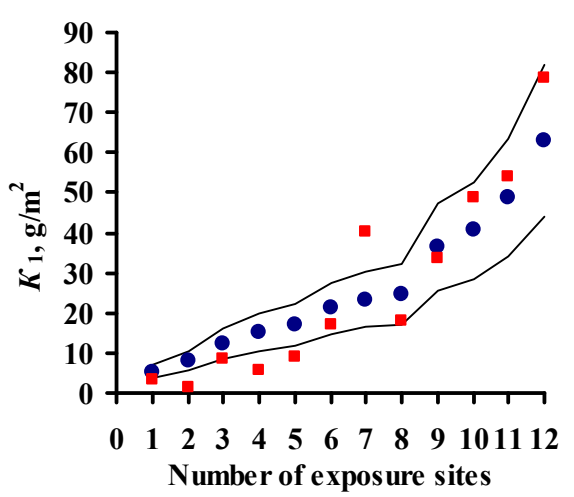

(b)

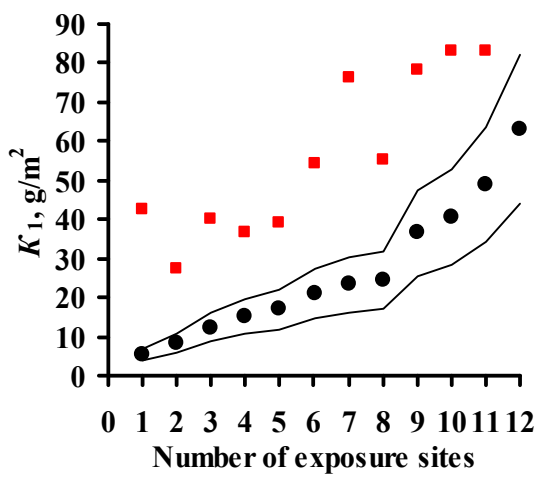

(c)

Figure 5. Carbon steel. RF program. $K_{1}$ predictions by the New DRF (a); Standard DRF (b); and Unified DRF (c). - experimental $K_{1}$ data; $\square-K_{1}$ predictions. Thin lines show the calculation error $( \pm 30 \%)$. The numbers of the exposure sites are given in accordance with Table 4.

If all DRFs give underestimated $K_{1} \mathrm{pr}$ values for the same locations, this may result from an inaccuracy of experimental data, i.e., corrosivity parameters and/or $K_{1}{ }^{\text {exp }}$ values. We did not perform any preliminary screening of the test locations. Therefore, it is reasonable to estimate the reliability of $K_{1} \exp$ only in certain locations by comparing them with other locations. Starting from No. 26, $K_{1}$ pr values are mostly either smaller or considerably smaller than $K_{1} \exp$. The locations with underestimated 
$K_{1}{ }^{\mathrm{pr}}$ that are common to all DRFs include: A4 (No. 5, No. 6), B1 (No. 28), B10 (No. 26), B11 (No. 41 ), E1 (No. 47, No. 48, No. 51), E4 (No. 43, 49, 50), EC1 (No. 45, No. 52, No. 56), CO3 (No. 40, 57 ), PE4 (No. 32, No. 39), M3 (No. 58, No. 60, No. 62). To perform the analysis, Table 6 was composed. It contains the test locations that, according to our estimates, have either questionable or reliable $K_{1} \exp$ values. It clearly demonstrates the unreliability of $K_{1}$ exp in some test locations. For example, in the test locations PE4 and A4, with $R H=33 \%-51 \%$ and TOW $=0.003-0.114$ of the year at background $\left[\mathrm{SO}_{2}\right], \mathrm{K}_{1} \exp$ are 4.5-16.5 $\mu \mathrm{m}\left(35.1-117 \mathrm{~g} / \mathrm{m}^{2}\right)$, while under more corrosive conditions in E8 and M2 with $\mathrm{RH}=52 \%-56 \%$ and $\mathrm{TOW}=0.100-0.200$ of the year and $\left[\mathrm{SO}_{2}\right]=6.7-9.9 \mu \mathrm{g} / \mathrm{m}^{3}, K_{1}$ exp values are also 3.3-15.2 $\mu \mathrm{m}$ $\left(25.7-118.6 \mathrm{~g} / \mathrm{m}^{2}\right)$. The impossibility of high $K_{1}$ values in PE4 and A4 is also confirmed by the 3D graph of the dependence of $\mathrm{K}$ on $\mathrm{SO}_{2}$ and TOW in [20]. Alternatively, for example, in B1, CO3 and B11 with $R H=75 \%-77 \%$ and $T O W=0.172-0.484$ of the year and $\left[\mathrm{SO}_{2}\right]=1-1.7 \mu \mathrm{g} / \mathrm{m}^{3}, K_{1} \exp =13.1-26.2 \mu \mathrm{m}$ $\left(102.2-204.4 \mathrm{~g} / \mathrm{m}^{2}\right)$, whereas in A2 and A3 with $\mathrm{RH}=72 \%-76 \%$ and $\mathrm{TOW}=0.482-0.665$ of the year and $\left[\mathrm{SO}_{2}\right]=1-10 \mu \mathrm{g} / \mathrm{m}^{3}, K_{1} \exp$ is as small as 5.6-16.1 $\mu \mathrm{m}\left(43.7-125.6 \mathrm{~g} / \mathrm{m}^{2}\right)$. The $K_{1}$ values reported for locations with uncertain data are 2-4 times higher than the $K_{1}$ values in trusted locations. The reason for potentially overestimated $K_{1}$ exp values being obtained is unknown. It may be due to non-standard sample treatment or to corrosion-related erosion. It can also be assumed that the researchers (performers) reported $K_{1}$ in $\mathrm{g} / \mathrm{m}^{2}$ rather than in $\mu \mathrm{m}$. If this assumption is correct, then $K_{1} \mathrm{pr}$ values would better match $K_{1} \exp$ (Figure 4 ). Unfortunately, we cannot compare the questionable $K_{1} \exp$ values with the $K_{1}{ }^{\exp }$ values rejected in the study where an artificial neural network was used [20]. We believe that, of the $K_{1}{ }^{\exp }$ values listed, only the data for the test locations up to No. 26 in Figure 4 can be deemed reliable.

For the RF program, the $K_{1}{ }^{\mathrm{pr}}$ values determined by the New DRF and the Standard DRF are pretty comparable with $K_{1} \exp$, but they are considerably higher for the Unified DRF (Figure 5).

The presented figures indicate that all DRFs which have the same parameters but different coefficients predict $K_{1}$ for same test locations with different degrees of reliability. That is, combinations of various coefficients in DRFs make it possible to obtain $K_{1}{ }^{\mathrm{pr}}$ results presented in Figures $3-5$. In view of this, the analysis of DRFs in order to explain the principal differences of $K_{1}{ }^{\mathrm{pr}}$ from $K_{1}{ }^{\exp }$ for each DRF appears interesting. 
Table 6. Atmosphere corrosivity parameters and first year corrosion losses of carbon steel in certain test locations under the MICAT project.

\begin{tabular}{|c|c|c|c|c|c|c|c|c|c|c|c|c|c|c|c|c|c|}
\hline \multicolumn{9}{|c|}{ Locations with Uncertain Data } & \multicolumn{9}{|c|}{ Locations with Trusted Data } \\
\hline \multirow{2}{*}{ Designation } & \multirow{2}{*}{ No. } & \multirow{2}{*}{$T,{ }^{\circ} \mathrm{C}$} & \multirow{2}{*}{$R H, \%$} & \multirow{2}{*}{$\begin{array}{c}\text { TOW, } \\
\text { 1/a }\end{array}$} & \multirow{2}{*}{$\begin{array}{l}\text { Prec, } \\
\mathrm{mm} / \mathrm{a}\end{array}$} & \multirow{2}{*}{$\begin{array}{l}{\left[\mathrm{SO}_{2}\right],} \\
\mu \mathrm{g} / \mathrm{m}^{3}\end{array}$} & \multicolumn{2}{|c|}{$K_{1}{ }^{\exp }$} & \multirow{2}{*}{ Designation } & \multirow{2}{*}{ No. } & \multirow{2}{*}{$T,{ }^{\circ} \mathrm{C}$} & \multirow{2}{*}{$R H, \%$} & \multirow{2}{*}{$\begin{array}{c}\text { TOW, } \\
\text { 1/a }\end{array}$} & \multirow{2}{*}{$\begin{array}{c}\text { Prec, } \\
\mathrm{mm} / \mathbf{a}\end{array}$} & \multirow{2}{*}{$\begin{array}{l}{\left[\mathrm{SO}_{2}\right],} \\
\mu \mathrm{g} / \mathrm{m}^{3}\end{array}$} & \multicolumn{2}{|c|}{$K_{1}{ }^{\exp }$} \\
\hline & & & & & & & $\mu \mathrm{m}$ & $\mathrm{g} / \mathrm{m}^{2}$ & & & & & & & & $\mu \mathrm{m}$ & $\mathrm{g} / \mathrm{m}^{2}$ \\
\hline PE4 & 32 & 16.4 & 37 & 0.003 & 17 & 1 & 15.0 & 117.0 & E8 & 3 & 8.8 & 52 & 0.100 & 738 & 9.1 & 3.3 & 25.7 \\
\hline PE4 & 39 & 17.2 & 33 & 0.020 & 34 & 1 & 16.5 & 128.7 & E8 & 4 & 6.9 & 52 & 0.100 & 624 & 8.9 & 3.6 & 28.1 \\
\hline $\mathrm{A} 4$ & 5 & 20.0 & 49 & 0.097 & 111 & 1 & 4.5 & 35.1 & E8 & 7 & 7.8 & 52 & 0.100 & 681 & 9 & 4.8 & 37.4 \\
\hline A4 & 6 & 18.0 & 51 & 0.114 & 35 & 1 & 4.6 & 35.9 & M2 & 29 & 21.0 & 56 & 0.200 & 1372 & 7.1 & 13.7 & 106.9 \\
\hline M3 & 58 & 18.0 & 62 & 0.161 & 374 & 10.9 & 26.4 & 205.9 & M2 & 33 & 21.0 & 56 & 0.190 & 1352 & 6.7 & 15.2 & 118.6 \\
\hline M3 & 62 & 18.0 & 51 & 0.161 & 374 & 31.1 & 37.5 & 292.5 & M2 & 22 & 21.0 & 56 & 0.212 & 1724 & 9.9 & 11.4 & 88.9 \\
\hline E1 & 47 & 11.1 & 63 & 0.241 & 334 & 1.18 & 19.7 & 153.7 & E5 & 16 & 15.0 & 59 & 0.126 & 258 & 5.4 & 6.8 & 53.0 \\
\hline E1 & 48 & 12.0 & 69 & 0.384 & 652 & 1.18 & 20.3 & 158.3 & M1 & 34 & 16.0 & 62 & 0.288 & 743 & 15.6 & 15.4 & 120.1 \\
\hline E1 & 51 & 10.6 & 65 & 0.271 & 495 & 1.18 & 22.5 & 175.5 & M1 & 9 & 15.4 & 64 & 0.288 & 743 & 17.5 & 5.1 & 39.8 \\
\hline E4 & 43 & 17.0 & 63 & 0.302 & 521 & 5.7 & 19.4 & 151.3 & M1 & 20 & 14.8 & 66 & 0.288 & 743 & 7.7 & 8.6 & 67.1 \\
\hline E4 & 49 & 18.1 & 65 & 0.390 & 554 & 8.3 & 20.3 & 158.3 & $\mathrm{~A} 2$ & 38 & 17.1 & 72 & 0.482 & 983 & 10.0 & 16.1 & 125.6 \\
\hline E4 & 50 & 17.2 & 62 & 0.316 & 374 & 1.9 & 21.0 & 163.8 & A2 & 36 & 16.7 & 75 & 0.578 & 1729 & 10.0 & 15.7 & 122.5 \\
\hline B10 & 26 & 20.4 & 69 & 0.442 & 1440 & 1 & 12.9 & 100.6 & A2 & 25 & 17.0 & 74 & 0.555 & 1420 & 9 & 12.4 & 96.7 \\
\hline B1 & 28 & 21.2 & 75 & 0.484 & 996 & 1.67 & 13.1 & 102.2 & A3 & 12 & 20.6 & 76 & 0.665 & 2158 & 1 & 5.7 & 44.5 \\
\hline $\mathrm{CO} 3$ & 40 & 27.0 & 76 & 0.330 & 900 & 1 & 17.0 & 132.6 & A3 & 13 & 20.9 & 74 & 0.631 & 2624 & 1 & 5.8 & 45.2 \\
\hline $\mathrm{CO} 3$ & 57 & 27.0 & 76 & 0.330 & 900 & 1 & 26.2 & 204.4 & A3 & 10 & 22.1 & 75 & 0.633 & 1720 & 1 & 5.6 & 43.7 \\
\hline EC1 & 52 & 26.9 & 82 & 0.661 & 635 & 2.72 & 22.6 & 176.3 & - & - & - & - & - & - & - & - & - \\
\hline
\end{tabular}




\subsection{Analysis of DRFs for Carbon Steel}

The DRFs were analyzed by comparison of the coefficients in Equations (3), (5) and (9). Nonlinear DRFs can be represented in the form:

$$
K_{1}=A \times\left[\mathrm{SO}_{2}\right]^{\alpha} \exp \left\{k_{1} \times R H+k_{2} \times(T-10)+k_{3} \times \text { Prec }\right\}
$$

or

$$
K_{1}=A \times\left[\mathrm{SO}_{2}\right]^{\alpha} \times \mathrm{e}^{k 1 \cdot R H} \times \mathrm{e}^{k 2 \cdot(T-10)} \times \mathrm{e}^{k 3 \cdot P r e c},
$$

where $A \times \mathrm{e}^{k 1 \cdot R H} \times \mathrm{e}^{k 2 \cdot(T-10)} \times \mathrm{e}^{k 3 \cdot P r e c}=K_{10}$.

The values of the coefficients used in Equations (3), (5) and (9) are presented in Table 7.

\begin{tabular}{|c|c|c|c|c|c|c|c|}
\hline \multirow{2}{*}{ DRF } & \multicolumn{2}{|c|}{$A$} & \multirow{2}{*}{$\alpha$} & \multirow{2}{*}{$k_{1}$} & \multicolumn{2}{|c|}{$k_{2}$} & \multirow{2}{*}{$k_{3}$} \\
\hline & $\mu \mathrm{m}$ & $\mathrm{g} / \mathrm{m}^{2}$ & & & $T \leq 10$ & $T>10$ & \\
\hline New & 0.99 & 7.7 & 0.47 & 0.024 & 0.095 & -0.095 & 0.00056 \\
\hline Standard & 1.77 & 13.8 & 0.52 & 0.020 & 0.150 & -0.054 & - \\
\hline Unified & 3.54 & 27.6 & 0.13 & 0.020 & 0.059 & -0.036 & - \\
\hline
\end{tabular}

Table 7. Values of coefficients used in the nonlinear DRFs for carbon steel.

To compare the $\alpha$ values, $K_{1}{ }^{\circ}=63 \mathrm{~g} / \mathrm{m}^{2}$ at $\left[\mathrm{SO}_{2}\right]=1 \mu \mathrm{g} / \mathrm{m}^{3}$ was used in Equation (8) for all DRFs. The $\left[\mathrm{SO}_{2}\right]^{\alpha}$ plots for all the DRFs for all programs are presented in Figure 1. For the New DRF, the line $K=f\left(\mathrm{SO}_{2}\right)$ was drawn approximately through the mean experimental points from all the test programs. Therefore, one should expect a uniform distribution of error $\delta$, e.g., in Figure 3a. For the Standard DRF, $\alpha=0.52$ is somewhat overestimated, which may result in more overestimated $K_{1}$ values at high $\left[\mathrm{SO}_{2}\right]$. However, in Figure $3 b$ for CS1 (No. 76), CS3 (No. 73, 74, 77) and GER10 (No. 76), $K_{1}{ }^{\mathrm{pr}}$ overestimation is not observed, apparently due to effects from other coefficients in DRF. For Unified DRF $\alpha=0.13$, which corresponds to a small range of changes in $K_{1}$ as a function of $\mathrm{SO}_{2}$. Therefore, in Figures $3 \mathrm{c}$ and $4 \mathrm{c}$, the $K_{1}{ }^{\mathrm{pr}}$ present a nearly horizontal band that is raised to the middle of the $K_{1}{ }^{\exp }$ range due to a higher value of $A=3.54 \mu \mathrm{m}\left(27.6 \mathrm{~g} / \mathrm{m}^{2}\right)$, Table 7 . As a result, the Unified DRF cannot give low $K_{1}{ }^{\mathrm{pr}}$ values for rural atmospheres, Figures $3 c$ and $5 c$, or high $K_{1} \mathrm{pr}$ values for industrial atmospheres, Figure $3 c$.

For the Linear DRF we present $K_{1} \mathrm{pr}^{\mathrm{p}}-\left[\mathrm{SO}_{2}\right]$ plots for TOW (fraction of a year) within the observed values: $0.043-0.876$ for ISO CORRAG program; $0.5-1$ based on the data in [19]; $0.17-0.62$ from UN/ECE program; 0.003-1 from the MICAT project, and 0.002-0.8 based on the data [20] for the MICAT project, Figure 1. One can see that reliable $\mathrm{K}_{1}{ }^{\mathrm{pr}}$ are possible in a limited range of TOW and $\left[\mathrm{SO}_{2}\right]$. The $K_{1}$ pr values are strongly overestimated at high values of these parameters (Figure $4 \mathrm{c}, \mathrm{d}$ ). That is, the Linear model has a limited applicability at combinations of TOW and $\left[\mathrm{SO}_{2}\right]$ that occur under natural conditions. Furthermore, according to the Linear DRF, the range of $K_{1} \mathrm{pr}^{\mathrm{r}}$ in clean atmosphere is $53-71 \mathrm{~g} / \mathrm{m}^{2}$, therefore the $K_{1}$ pr values in clean atmosphere lower than $53 \mathrm{~g} / \mathrm{m}^{2}$ (Figures $3 \mathrm{~d}$ and $4 \mathrm{~d}$,e) or above $71 \mathrm{~g} / \mathrm{m}^{2}$ cannot be obtained. Higher $K_{1}{ }^{\mathrm{pr}}$ values can only be obtained due to $\left[\mathrm{SO}_{2}\right]$ contribution. The underestimated $K_{1}{ }^{\mathrm{pr}}$ values in comparison with $K_{1}{ }^{\exp }$ for the majority of test locations (Figure $3 \mathrm{~d}$ ) are apparently caused by the fact that the effects of other parameters, e.g., $T$, on corrosion are not taken into account.

Figure 6 compares $K=f\left(\mathrm{SO}_{2}\right)$ for all the models with the graphical representation of the dependence reported in [20] (for $\left[\mathrm{SO}_{2}\right], \mathrm{mg} /\left(\mathrm{m}^{2} \cdot \mathrm{d}\right.$ ) values were converted to $\mu \mathrm{g} / \mathrm{m}^{3}$ ). The dependence in [20] is presented for a constant temperature, whereas the dependences given by DRFs are given for average values in the entire range of meteorological parameters in the test locations. Nevertheless, the comparison is of interest. Below 70 and $80 \mu \mathrm{g} / \mathrm{m}^{3}$, according to [20], $K$ has lower values than those determined by the New DRF and Standard DRF, respectively, while above these values, $K$ has higher values. According to the Unified DRF, $K$ has extremely low values at all $\left[\mathrm{SO}_{2}\right]$ values, whereas according to the Linear DRF (TOW from 0.03 to 1 ), the values at TOW $=1$ are extremely high even at small $\left[\mathrm{SO}_{2}\right]$. 


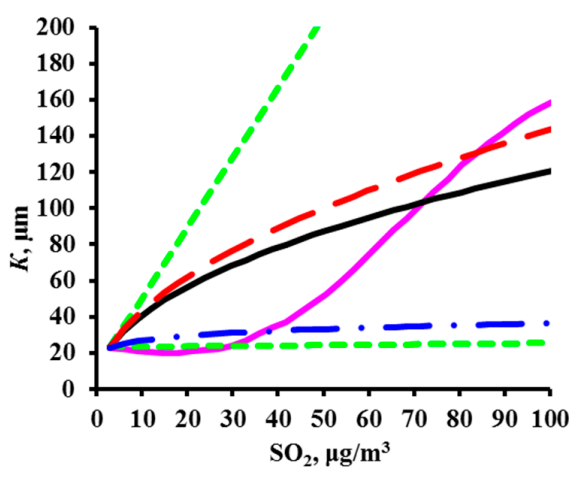

Figure 6. Comparison of $K=f\left(\mathrm{SO}_{2}\right)$ plots for the DRF presented in [20]. -- plot according to [20], -by the New DRF; -- by the Standard DRF; -•- by the Unified DRF; --- by the Linear DRF [20].

To perform a comparative estimate of $k_{1}$ and $k_{2}$, let us use the value $T_{\text {lim }}=10{ }^{\circ} \mathrm{C}$ accepted in the DRF, i.e., where the temperature dependence changes. Furthermore, it is necessary to know the $K_{1}$ value in clean atmosphere at $T_{\lim }$ and at the $R H$ that is most common at this temperature. These data are unknown at the moment. Therefore, we'll assume that at $T_{\text {lim }}=10^{\circ} \mathrm{C}$ and $R H=75 \%$, $K=63 \mathrm{~g} / \mathrm{m}^{2}$. The dependences of $K$ on $T$ and $R H$ under these conditions and with consideration for the corresponding $k_{1}$ and $k_{2}$ for each DRF are presented in Figure 7.

The nearly coinciding $k_{1}$ values ( 0.020 for the Unified DRF and Standard DRF, and 0.024 for the New DRF, Table 8) result in an insignificant difference in the $R H$ effect on $K$ (Figure 7a).

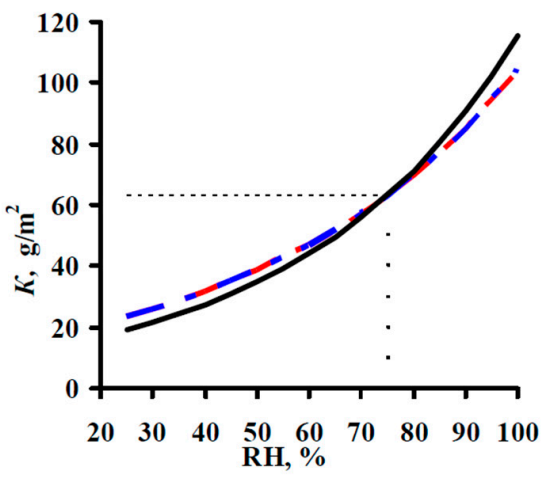

(a)

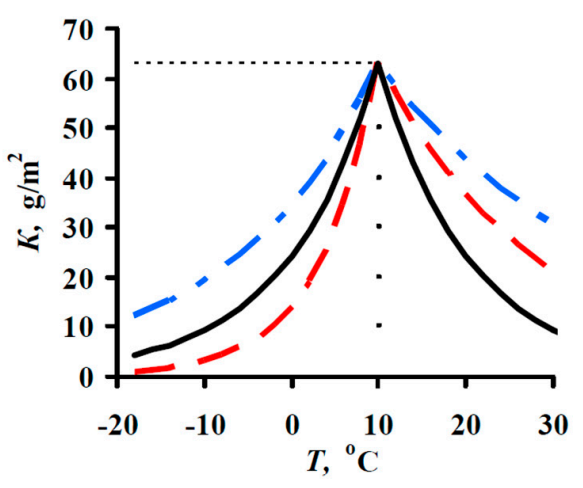

(b)

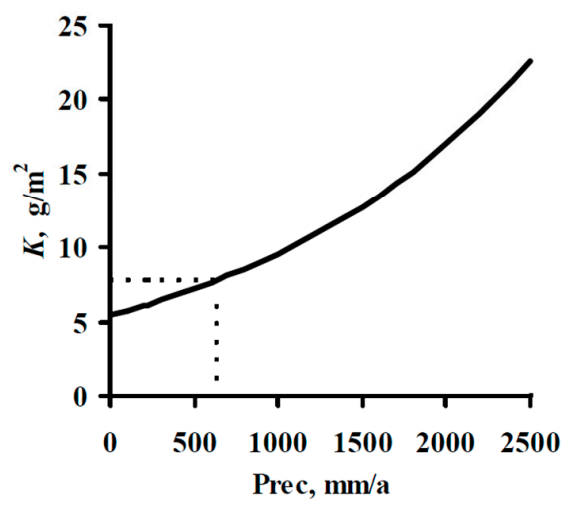

(c)

Figure 7. Variation of $K$ for carbon steel vs. relative humidity (a), temperature (b). and Prec (c) with account for the values of the DRF coefficients. - - by the New DRF; - - by the Standard DRF; - - - by the Unified DRF. 
Table 8. Values of coefficients used in the nonlinear DRFs for zinc.

\begin{tabular}{|c|c|c|c|c|c|c|c|c|c|}
\hline \multirow{2}{*}{ DRF } & \multicolumn{2}{|c|}{$A$} & \multirow{2}{*}{$\alpha$} & \multirow{2}{*}{$k_{1}$} & \multicolumn{2}{|c|}{$k_{2}$} & \multirow{2}{*}{$k_{3}$} & \multicolumn{2}{|c|}{$B$} \\
\hline & $\mu \mathrm{m}$ & $\mathrm{g} / \mathrm{m}^{2}$ & & & $T \leq 10$ & $T>10$ & & $\mu \mathrm{g}$ & $\mathrm{g} / \mathrm{m}^{2}$ \\
\hline New & 0.0986 & 0.71 & 0.28 & 0.022 & 0.045 & -0.085 & 0.0001 & - & - \\
\hline Standard & 0.0129 & 0.0929 & 0.44 & 0.046 & 0.038 & -0.071 & - & - & - \\
\hline Unified & 0.188 & 1.35 & 0.22 & 0.018 & 0.062 & -0.021 & - & 0.00403 & 0.029 \\
\hline
\end{tabular}

The temperature coefficient $k_{2}$ has a considerable effect on $K$. For the Unified $D R F$, the $k_{2}$ values of $0.059(-0.036)$ for $T \leq 10^{\circ} \mathrm{C}\left(T>10^{\circ} \mathrm{C}\right)$ create the lowest decrease in $K$ with a $T$ decrease (increase) in comparison with the other DRFs (Figure $7 \mathrm{~b}$ ). A consequence of such $k_{2}$ values can be demonstrated by examples. Due to the temperature effect alone, $K \sim 15 \mathrm{~g} / \mathrm{m}^{2}$ at $T=-12{ }^{\circ} \mathrm{C}$ (Figure $7 \mathrm{~b}$ ) and $K \sim 45 \mathrm{~g} / \mathrm{m}^{2}$ at $T=20^{\circ} \mathrm{C}$. The effects of other parameters and account for the $A$ value would result in even more strongly overestimated $\mathrm{K}^{\mathrm{pr}}$ values. For comparison: in Bilibino at $T=-12.2^{\circ} \mathrm{C}$ and $R H=80 \%$, $K_{1}{ }^{e x p}=5.4 \mathrm{~g} / \mathrm{m}^{2}$ (Table 4 ) and $K^{\mathrm{pr}}=42 \mathrm{~g} / \mathrm{m}^{2}$ (Figure 5). In A3 test location, at $T=20.6^{\circ} \mathrm{C}$ and $R H=76 \%$, $K_{1}{ }^{\exp }=44.5 \mathrm{~g} / \mathrm{m}^{2}$ (Table 4), while due to $A$ and other parameters, $K_{1}{ }^{\mathrm{pr}}=86.2 \mathrm{~g} / \mathrm{m}^{2}$, Figure $4 \mathrm{c}$.

In the Standard DRF, the $k_{2}$ values are higher than in the Unified DRF: 0.150 and -0.054 for $T \leq 10^{\circ} \mathrm{C}$ and $T>10{ }^{\circ} \mathrm{C}$, respectively, so a greater $K$ decrease is observed, especially at $T \leq 10{ }^{\circ} \mathrm{C}$, Figure $7 \mathrm{~b}$. At low $T$, the $K$ values are small, e.g., $K \sim 2 \mathrm{~g} / \mathrm{m}^{2}$ at $T=-12{ }^{\circ} \mathrm{C}$. In $K_{1}$ pr calculations, the small $K$ are made higher due to $A$, and they are higher in polluted atmospheres due to higher $\alpha=0.52$. As a result, $K^{\mathrm{pr}}$ are quite comparable with $K^{\mathrm{exp}}$, Figure $3 \mathrm{~b}$. However, let us note that $K^{\mathrm{pr}}$ is considerably lower than $K^{\exp }$ in many places. Perhaps, this is due to an abrupt decrease in $K$ in the range $T \leq 10^{\circ} \mathrm{C}$. This temperature range is mostly met in test locations under the UN/ECE program.

In the New DRF, $k_{2}$ has an intermediate value at $T \leq 10^{\circ} \mathrm{C}$ and the lowest value at $T>10^{\circ} \mathrm{C}$, whereas $A$ has the lowest value. It is more difficult to estimate the $k_{2}$ value with similar $k_{2}$ values in the other DRFs, since the New DRF uses one more member, i.e., $\mathrm{e}^{k 3 \cdot P r e c}$. The dependence of $K$ on Prec is presented in Figure 7c. The following arbitrary values were used to demonstrate the possible effect of Prec on K: K = 7.8 g/m $/ \mathrm{m}^{2}$ at Prec $=632 \mathrm{~mm} /$ year. For example, in location PE5 (UN/ECE program) with Prec $=632 \mathrm{~mm} /$ year, $K=7.8 \mathrm{~g} / \mathrm{m}^{2}$ at $T=12.2{ }^{\circ} \mathrm{C}$ and $R H=67 \%$. The maximum Prec was taken as $2500 \mathrm{~mm}$ /year, e.g., it is $2144 \mathrm{~mm} /$ year in NOR23 (UN/ECE program) and $2395 \mathrm{~mm} /$ year in B8 (MICAT project). It follows from the figure that, other conditions being equal, $K$ can increase from 5.4 to $22.6 \mathrm{~g} / \mathrm{m}^{2}$ just due to an increase in Prec from 0 to $2500 \mathrm{~mm} /$ year at $k_{3}=0.00056$ (Table 7).

Thus, it has been shown that the coefficients for each parameter used in the DRFs vary in rather a wide range. The most reliable $K_{1}{ }^{\mathrm{pr}}$ can be reached if, in order to find the most suitable coefficients, the DRFs are based on the $K=f\left(\mathrm{SO}_{2}\right)$ relationship obtained.

\subsection{Predictions of $K_{1}$ Using Various DRFs for Zinc}

The results on $K_{1} \mathrm{pr}^{\mathrm{f}}$ for zinc for the UN/ECE program, MICAT project, and RF program are presented in Figures 8-10, respectively. In the UN/ECE program, the differences between the $K_{1}{ }^{p r}$ and $K_{1}{ }^{\exp }$ values for zinc are more considerable than those for carbon steel. This may be due not only to the imperfection of the DRFs and the inaccuracy of the parameters and $K_{1}{ }^{\text {exp }}$, but also to factors unaccounted for in DRFs that affect zinc. For all the DRFs, the $K_{1}{ }^{\mathrm{pr}}$ values match $K_{1}{ }^{\exp }$ to various extent; some of the latter exceed the error $\delta( \pm 30 \%)$. Let us estimate the discrepancy between $K_{1}{ }^{\mathrm{pr}}$ and $K_{1}{ }^{\exp }$ for those $K_{1}{ }^{\mathrm{pr}}$ that exceed $\delta$. For the New DRF (Figure 8a) and the Standard DRF (Figure 8b), overestimated $K_{1}{ }^{\mathrm{pr}}$ values are observed for low and medium $K_{1}{ }^{\exp }$, while underestimated ones are observed for medium and high $K_{1}{ }^{\text {exp }}$. In general, the deviations of $K_{1}{ }^{\text {pr }}$ from $K_{1}{ }^{\exp }$ are symmetrical for these DRFs, but the scatter of $K_{1} \mathrm{pr}$ is greater for the Standard DRF. For Unified DRF (Figure $8 \mathrm{c}$ ), $K_{1} \mathrm{pr}$ are mostly overestimated, considering that the $\Delta K^{[\mathrm{H}+]}=0.029 \mathrm{Rain}\left[\mathrm{H}^{+}\right]$component was not taken into account for some test locations due to the lack of data on $\left[\mathrm{H}^{+}\right]$. The $\Delta K^{[\mathrm{H}+]}$ value can be significant, e.g., $2.35 \mathrm{~g} / \mathrm{m}^{2}$ in US39 or $5.13 \mathrm{~g} / \mathrm{m}^{2}$ in CS2. 


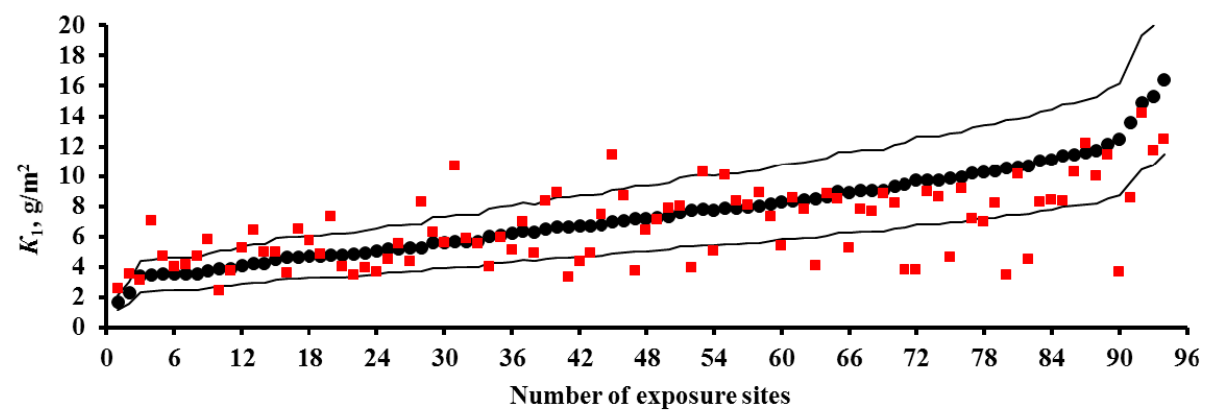

(a)

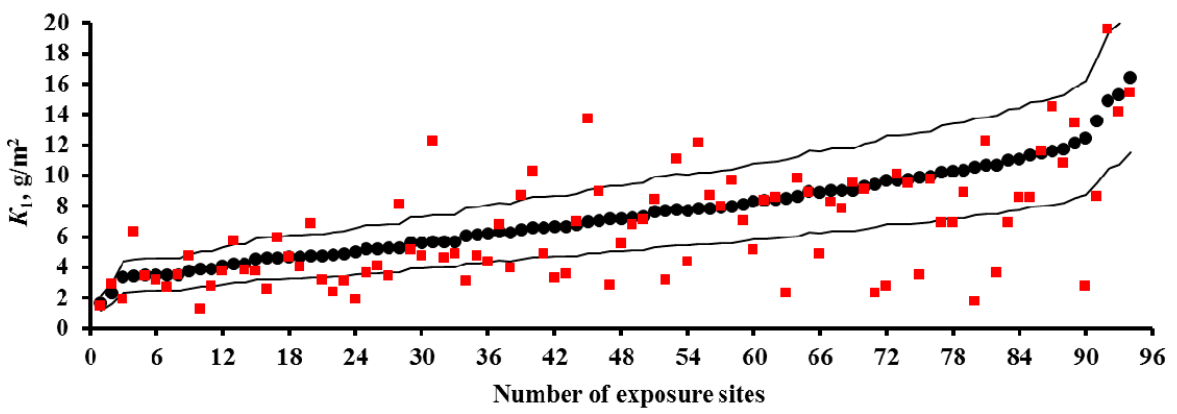

(b)

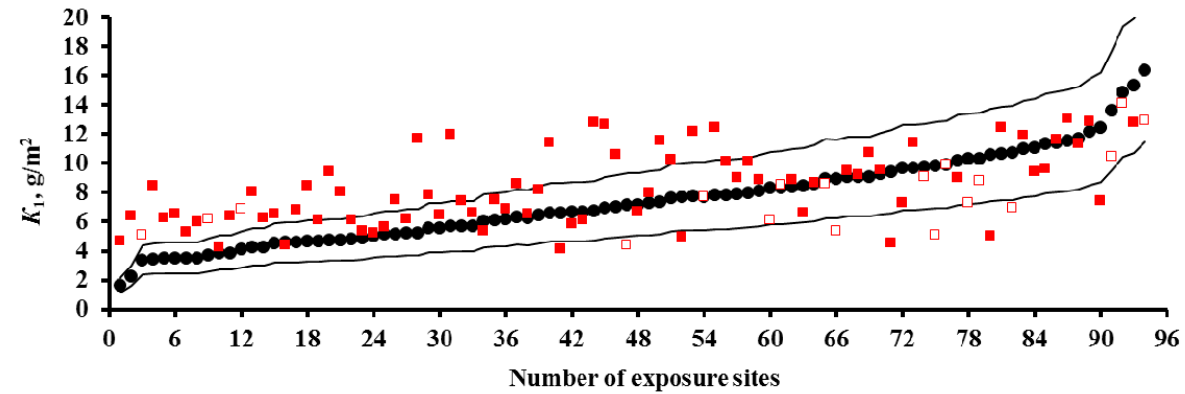

(c)

Figure 8. Zinc. UN/ECE program. $K_{1}$ predictions by the New DRF (a); Standard DRF (b); and Unified $\mathrm{DRF}(\mathbf{c})$. $\bullet$ experimental $K_{1}$ data; $\square-K_{1}$ predictions. $\square-K_{1}$ predictions without taking $\left[\mathrm{H}^{+}\right]$into account (only for the Unified DRF). Thin lines show the calculation error $( \pm 30 \%)$. The numbers of the exposure sites are given in accordance with Table 2.

With regard to the MICAT project, the New and Unified DRFs (Figure 9a,c) give overestimated $K_{1}{ }^{\mathrm{pr}}$ at low $K_{1}{ }^{\exp }$, but the Standard DRF gives $K_{1}{ }^{\mathrm{pr}}$ values comparable to $K_{1}{ }^{\exp }$ (Figure $9 \mathrm{~b}$ ). Starting from test locations No. 33-No. 36 , the $K_{1}{ }^{p r}$ values for all the DRFs are underestimated or significantly underestimated. It is evident from Figure $2 b$ that rather many test locations with small $\left[\mathrm{SO}_{2}\right]$ have extremely high $K_{1}{ }^{\exp }$. This fact confirms the uncertainty of experimental data from these locations, as shown for carbon steel as well. The following test locations can be attributed to this category: A3 (No. 43, No. 44, No. 53), B10 (No. 50), B11 (No. 49), B12 (No. 57), CO2 (No. 55, No. 58, No. 60), CO3 (No. 54, No. 61), PE6 (No. 36, No. 38), and M3 (No. 35, No. 59). There is little sense in making $K_{1}$ predictions for these locations. 


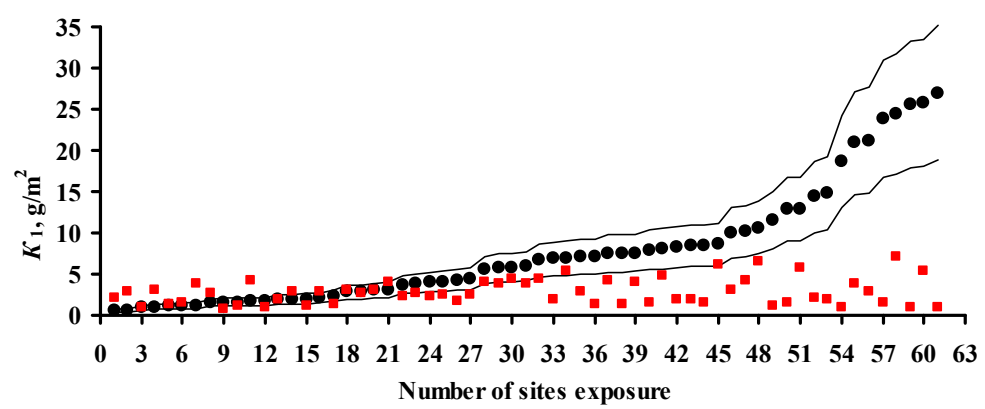

(a)

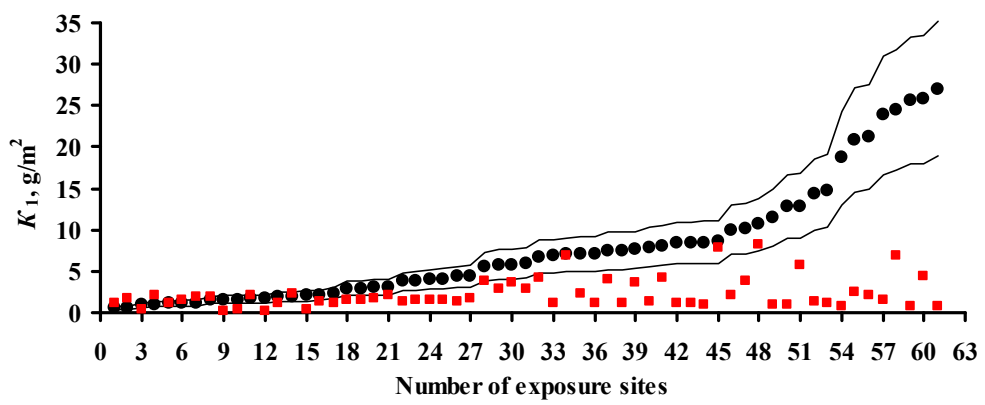

(b)

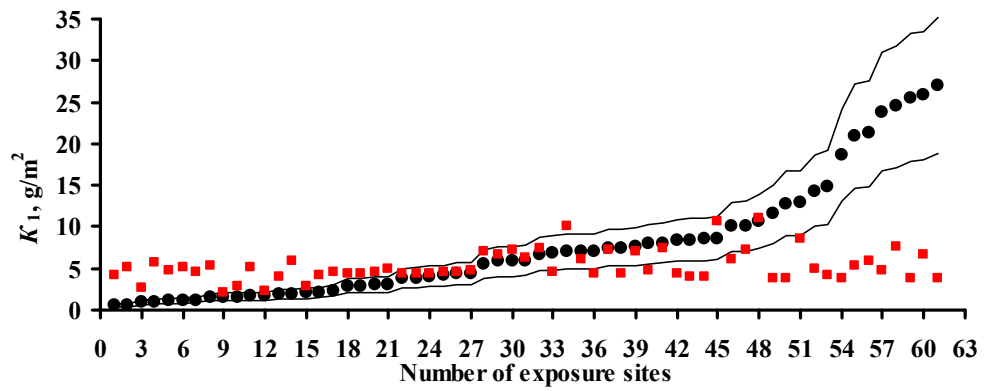

(c)

Figure 9. Zinc. MICAT program. $K_{1}$ predictions by the New DRF (a); Standard DRF (b); and Unified DRF (c). - experimental $K_{1}$ data; $-K_{1}$ predictions. Thin lines show the calculation error $( \pm 30 \%)$. The numbers of the exposure sites are given in accordance with Table 3.

For the RF program, the $K_{1}{ }^{\mathrm{pr}}$ values calculated by the New and Unified DRFs are more comparable to $K_{1}$ exp than those determined using the Standard DRF (Figure 10).

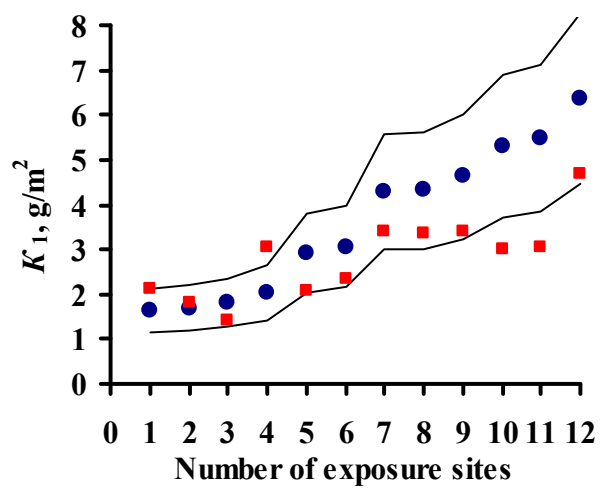

(a)

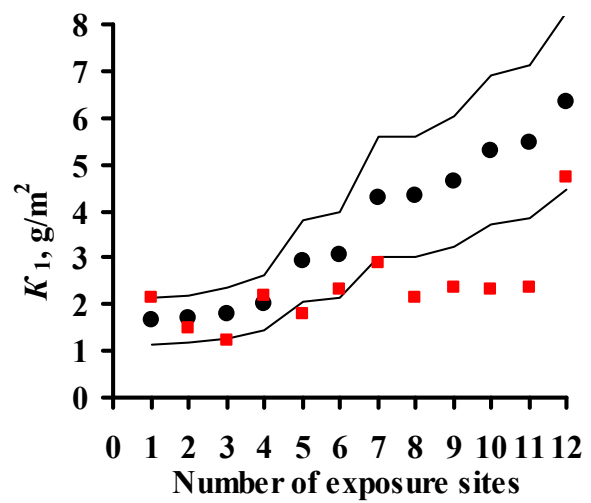

(b)

Figure 10. Cont. 


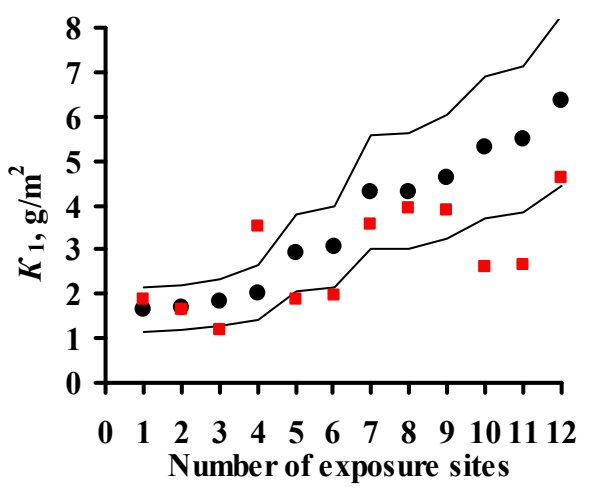

(c)

Figure 10. Zinc. RF program. $K_{1}$ predictions by the New DRF (a); Standard DRF (b); and Unified $\operatorname{DRF}(\mathbf{c})$. - experimental $K_{1}$ data; $\square-K_{1}$ predictions. Thin lines show the calculation error $( \pm 30 \%)$. The numbers of the exposure sites are given in accordance with Table 4.

\subsection{Analysis of DRFs for Zinc}

As for steel, DRFs were analyzed by comparison of their coefficients. The nonlinear DRFs for zinc can be represented in the form:

$$
K_{1}=A \times\left[\mathrm{SO}_{2}\right]^{\alpha} \times \exp \left\{k_{1} \times R H+k_{2} \times(T-10)+k_{3} \times \text { Prec }\right\}+B \times R a i n \times\left[\mathrm{H}^{+}\right]
$$

or

$$
K_{1}=A \times\left[\mathrm{SO}_{2}\right]^{\alpha} \times \mathrm{e}^{k 1 \cdot R H} \times \mathrm{e}^{k 2 \cdot(T-10)} \times \mathrm{e}^{k 3 \cdot \operatorname{Prec}}+B \times \operatorname{Rain} \times\left[\mathrm{H}^{+}\right] .
$$

The values of the coefficients used in Equations (4), (6) and (10) are presented in Table 8.

To compare the $\alpha$ values, $K_{1}=4 \mathrm{~g} / \mathrm{m}^{2}$ at $\left[\mathrm{SO}_{2}\right]=1 \mu \mathrm{g} / \mathrm{m}^{3}$ was used for all DRFs. Let us note that the value $K_{1}=4 \mathrm{~g} / \mathrm{m}^{2}$ was obtained during the estimation of $K=f\left(\mathrm{SO}_{2}\right)$ for the development of the New DRF. The plots for all the programs are presented in Figure 2. For the New DRF, the line at $\alpha=0.28$ mostly passes through the average experimental points. For the Standard DRF, $\alpha=0.44$ is overestimated considerably, which may result in overestimated $K_{1} \mathrm{pr}^{\mathrm{r}}$, especially at high $\left[\mathrm{SO}_{2}\right]$. For the Unified DRF at $\alpha=0.22$, the line passes, on average, slightly below the experimental points. The low $\alpha$ value, as for carbon steel, does not give a wide range of $K$ values as a function of $\left[\mathrm{SO}_{2}\right]$, which may result in underestimated $\mathrm{K}_{1} \mathrm{pr}$, especially at high $\left[\mathrm{SO}_{2}\right]$.

Let us assume for a comparative estimate of $k_{1}$ and $k_{2}$ that $K=4 \mathrm{~g} / \mathrm{m}^{2}$ in a clean atmosphere at $T_{\text {lim }}=10{ }^{\circ} \mathrm{C}$ and $R H=75 \%$. Figure 11 demonstrates the plots of $K$ versus these parameters under these starting conditions. The Standard DRF $\left(k_{1}=0.46\right)$ shows an abrupt variation in $K$ vs. $R H$. According to this relationship, at the same temperature, the $K$ value should be $0.5 \mathrm{~g} / \mathrm{m}^{2}$ at $R H=30 \%$ and $12.6 \mathrm{~g} / \mathrm{m}^{2}$ at $R H=100 \%$. According to the New DRF and Unified DRF with $k_{1}=0.22$ and 0.18 , respectively, the effect of $R H$ is weaker, therefore $K=1.5$ and $1.8 \mathrm{~g} / \mathrm{m}^{2}$ at $R H=30 \%$, respectively, and $K=6.9$ and $6.4 \mathrm{~g} / \mathrm{m}^{2}$ at $R H=100 \%$, respectively.

The effect of temperature on $K$ is shown in Figure 11b. In the New DRF, $k_{2}=0.045$ at $T \leq 10^{\circ} \mathrm{C}$ has an intermediate value; at $T>10^{\circ} \mathrm{C}, k_{2}=-0.085$ has the largest absolute value, which corresponds to an abrupt decrease in $K$ with an increase in temperature. In the Unified DRF, $k_{2}=-0.021$ at $T>10^{\circ} \mathrm{C}$, i.e., an increase in temperature results in a slight decrease in $K$. As for the effect of $A$, this also contributes to higher $K_{1}{ }^{p r}$ values despite the small $\alpha$ value. 


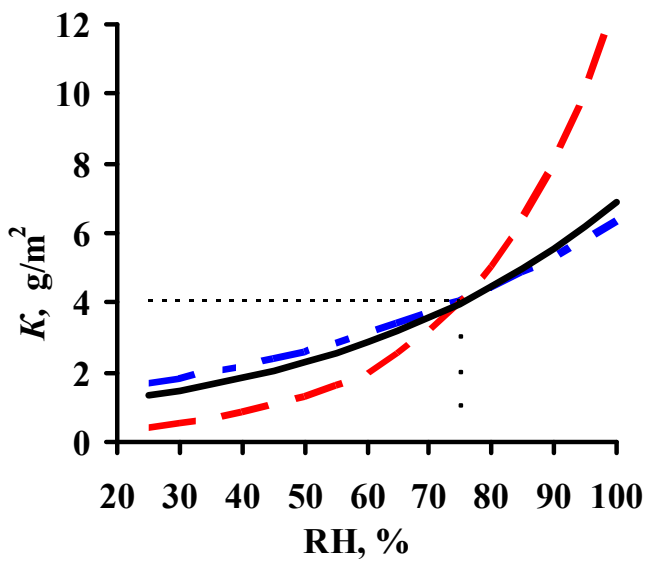

(a)

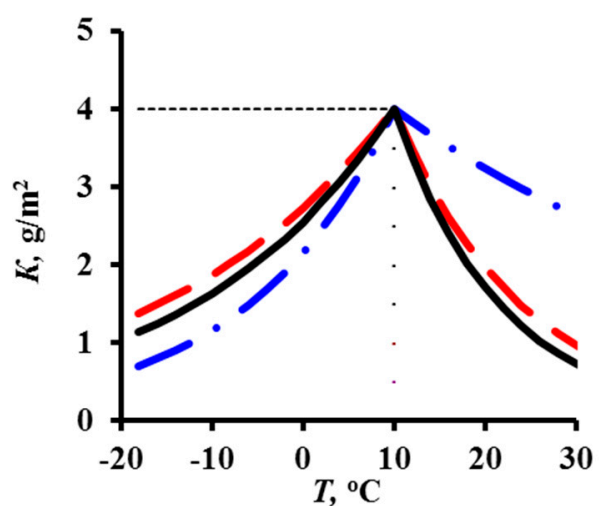

(b)

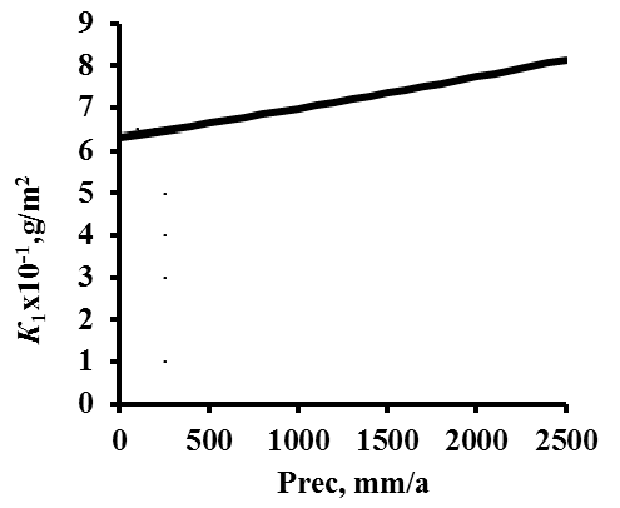

(c)

Figure 11. Variation of $K$ for zinc versus relative humidity (a), temperature (b) and Prec (c) with account for the values of the DRF coefficients. -- by the New DRF; -- by the Standard DRF; - •- by the Unified DRF.

In the Standard DRF, the value $A=0.0929\left(\mathrm{~g} / \mathrm{m}^{2}\right)$, which is $\sim 8$ times smaller than in the New $\mathrm{DRF}$, and a small $k_{2}=-0.71$ at $T>10{ }^{\circ} \mathrm{C}$ were taken to compensate the $K_{1} \mathrm{pr}$ overestimation due to the combination of high values, $\alpha=0.44$ and $k_{1}=0.46$. In the Unified DRF, the high $A$ value that is $\sim 2$ times higher than in the New DRF is not compensated by the combination of the low values, $\alpha=0.22$ and $k_{2}=-0.021$ at $T>10^{\circ} \mathrm{C}$. Therefore, the $K_{1}$ pr values are mostly overestimated, Figures $8 \mathrm{c}$ and $9 \mathrm{c}$ for trusted test locations. However, small $K_{1}$ pr values were attained for low $T$ at $k_{2}=0.62$, Figure 10c.

The effect of Prec on $K$ at $k_{3}=0.0001$, which is taken into account only in the New DRF, given under the assumption that $K=0.65$ in a clean atmosphere at Prec (Rain) $=250 \mathrm{~mm} /$ year, $T=15^{\circ} \mathrm{C}$ and $R H=60 \%$ (e.g., location E5 in the MICAT project), is shown in Figure 11c. Upon an increase in Prec (Rain) from 250 to $2500 \mathrm{~mm} /$ year, $K$ can increase from 0.65 to $0.81 \mathrm{~g} / \mathrm{m}^{2}$.

As for carbon steel, the above analysis of coefficients in the DRFs for zinc confirms that the coefficients can be varied to obtain reliable $K_{1}$ pr values. The New DRF based on $K=f\left(\mathrm{SO}_{2}\right)$ gives the most reliable $K_{1}{ }^{\text {pr }}$ values for zinc.

\section{Estimation of Coefficients in DRFs for Carbon Steel and Zinc}

Let us first note that the starting conditions that we took to demonstrate the effect of various atmosphere corrosivity parameters on $K$ of carbon steel and zinc (Figures 7 and 11) may not match the real values. However, the plots obtained give an idea on $K$ variations depending on the coefficients in the DRFs. 
For continental test locations under all programs, the $K_{1}$ exp values are within the following ranges: for carbon steel, from 6.3 (Oimyakon, RF program) to $577 \mathrm{~g} / \mathrm{m}^{2}$ (CS3, UN/ECE program); for zinc, from 0.65 (E5, MICAT project) to $16.41 \mathrm{~g} / \mathrm{m}^{2}$ (CS3, UN/ECE program). That is, the difference in the corrosion losses is at least $\sim 10-35$ fold, the specific densities of these metals being nearly equal. Higher $K_{1}{ }^{\mathrm{pr}}$ values for steel than for zinc are attained using different coefficients at the parameters in the DRFs.

In the New DRFs, $A$ is 7.7 and $0.71 \mathrm{~g} / \mathrm{m}^{2}$ for carbon steel and zinc, respectively, i.e., the difference is $\sim 10$-fold. Higher $K_{1}{ }^{\mathrm{pr}}$ values for steel than for zinc were obtained chiefly due to the contribution of $\left[\mathrm{SO}_{2}\right]^{\alpha}$ at $\alpha=0.47$ and 0.28 , respectively. The values of $R H$ and Prec affect the corrosion of steel more strongly than they affect zinc corrosion. The coefficients for these parameters are: $k_{1}=0.024$ and $0.022 ; k_{3}=0.00056$ and 0.0001 for steel and zinc, respectively. However, the temperature coefficients ( $k_{2}=0.095$ and -0.095 for steel; $k_{2}=0.045$ and -0.085 for zinc) indicate that, with a deviation of $T$ from $10{ }^{\circ} \mathrm{C}$, the corrosion process on steel is hindered to a greater extent than on zinc.

In the Standard DRF, $A$ is 1.77 and $0.0129 \mu \mathrm{m}$ for carbon steel and zinc, respectively, i.e., the difference is $\sim 137$-fold. The $\alpha$ value for steel is somewhat higher than that for zinc, i.e., 0.52 and 0.44 respectively, which increases the difference of $K_{1}$ pr for steel from that for zinc. As shown above, the difference should not be greater than 35-fold. This difference is compensated by the 2.3-fold higher effect of $R H$ on zinc corrosion than on steel corrosion $\left(k_{1}=0.046\right.$ and 0.020 for zinc and steel, respectively). Furthermore, the temperature coefficient $k_{2}$ at $T \leq 10{ }^{\circ} \mathrm{C}$ for steel is 3.95 times higher than that for zinc. This indicates that steel corrosion slows down abruptly in comparison with zinc as $T$ decreases below $10{ }^{\circ} \mathrm{C}$. At $T>10{ }^{\circ} \mathrm{C}$, the $k_{2}$ values for steel and zinc are comparable. Taking the values of the coefficients presented into account, the $K_{1}$ pr values for steel are 15-fold higher, on average, than those for zinc at $T \leq 10^{\circ} \mathrm{C}$, but $\sim 60$-fold at $T>10^{\circ} \mathrm{C}$. Of course, this is an approximate estimate of the coefficients used in the Standard DRF.

In the Unified DRF, $A$ is 3.54 and $0.188 \mu \mathrm{m}$ for carbon steel and zinc, respectively, i.e., the difference is $\sim 19$-fold. The $\alpha$ value for steel is lower than that for zinc, i.e., 0.13 and 0.22 respectively, which decreases the difference of $K_{1}{ }^{\mathrm{pr}}$ of steel from that of zinc. Conversely, the $R H$ value affects steel corrosion somewhat more strongly than that of zinc $\left(k_{1}=0.020\right.$ and 0.018 for steel and zinc, respectively). The $k_{2}$ values for steel and zinc are comparable in both temperature ranges. The $\Delta K^{[\mathrm{H}+]}$ component was introduced only for zinc, which somewhat complicates the comparison of the coefficients in these DRFs.

All the presented DRFs are imperfect not only because of the possible inaccuracy of the mathematical expressions as such, but also due to the inaccuracy of the coefficients used in the DRFs. The $K_{1}$ pr values obtained using the New DRF match $K_{1}$ exp most accurately. However, while the $\alpha$ values that were assumed to be 0.47 and 0.28 for carbon steel and zinc, respectively, may be considered as accurate in a first approximation, the other coefficients need to be determined more accurately by studying the effect of each atmosphere corrosivity parameter on corrosion, with the other parameters being unchanged. Studies of this kind would allow each coefficient to be estimated and DRFs for reliable prediction of $K_{1}$ in atmospheres with various corrosivity to be created.

\section{Conclusions}

1. $K=f\left(\mathrm{SO}_{2}\right)$ plots of corrosion losses of carbon steel and zinc vs. sulfur dioxide concentration were obtained to match, to a first approximation, the mean meteorological parameters of atmosphere corrosivity.

2. Based on the $K=f\left(\mathrm{SO}_{2}\right)$ relationships obtained, with consideration for the nonlinear effect of temperature on corrosion, New DRFs for carbon steel and zinc in continental territories were developed.

3. Based on the corrosivity parameters at test locations under the UN /ECE and RF programs and the MICAT project, predictions of first-year corrosion losses of carbon steel and zinc were given using the New DRF, Standard DRF, and Unified DRF, as well as the linear model for carbon steel obtained in [20] with the aid of an artificial neural network. The predicted corrosion losses are 
compared with the experimental data for each DRF. It was shown that the predictions provided by the New DRFs for the first-year match the experimental data most accurately.

4. An analysis of the values of the coefficients used in the DRFs for the prediction of corrosion losses of carbon steel and zinc is presented. It is shown that more accurate DRFs can be developed based on quantitative estimations of the effects of each atmosphere corrosivity parameter on corrosion.

Acknowledgments: We are grateful to Manuel Morcillo for valuable comments.

Author Contributions: Y.M.P. performed the modelling and analysis and wrote the paper. A.I.M. contributed the discussion of the data.

Conflicts of Interest: The authors declare no conflict of interest.

\section{References}

1. McCuen, R.H.; Albrecht, P.; Cheng, J.G. A New Approach to Power-Model Regression of Corrosion Penetration Data. In Corrosion Forms and Control for Infrastructure; Chaker, V., Ed.; American Society for Testing and Materials: Philadelphia, PA, USA, 1992.

2. Syed, S. Atmospheric corrosion of materials. Emir. J. Eng. Res. 2006, 11, 1-24.

3. De la Fuente, D.; Castano, J.G.; Morcillo, M. Long-term atmospheric corrosion of zinc. Corros. Sci. 2007, 49, 1420-1436. [CrossRef]

4. Landolfo, R.; Cascini, L.; Portioli, F. Modeling of metal structure corrosion damage: A state of the art report. Sustainability 2010, 2, 2163-2175. [CrossRef]

5. Morcillo, M.; de la Fuente, D.; Diaz, I.; Cano, H. Atmospheric corrosion of mild steel (article review). Rev. Metal. 2011, 47, 426-444. [CrossRef]

6. De la Fuente, D.; Diaz, I.; Simancas, J.; Chico, B.; Morcillo, M. Long-term atmospheric corrosion of mild steel. Corros. Sci. 2011, 53, 604-617. [CrossRef]

7. Morcillo, M.; Chico, B.; Diaz, I.; Cano, H.; de la Fuente, D. Atmospheric corrosion data of weathering steels: A review. Corros. Sci. 2013, 77, 6-24. [CrossRef]

8. Surnam, B.Y.R.; Chiu, C.W.; Xiao, H.P.; Liang, H. Long term atmospheric corrosion in Mauritius. CEST 2015, 50, 155-159. [CrossRef]

9. Panchenko, Y.M.; Marshakov, A.I. Long-term prediction of metal corrosion losses in atmosphere using a power-linear function. Corros. Sci. 2016, 109, 217-229. [CrossRef]

10. Corrosion of Metals and Alloys-Corrosivity of Atmospheres-Guiding Values for the Corrosivity Categories; ISO 9224:2012(E); International Standards Organization: Geneva, Switzerlands, 2012.

11. Rosales, B.M.; Almeida, M.E.M.; Morcillo, M.; Uruchurtu, J.; Marrocos, M. Corrosion y Proteccion de Metales en las Atmosferas de Iberoamerica; Programma CYTED: Madrid, Spain, 1998; pp. 629-660.

12. Tidblad, J.; Kucera, V.; Mikhailov, A.A. Statistical Analysis of 8 Year Materials Exposure and Acceptable Deterioration and Pollution Levels; UN/ECE ICP on Effects on Materials; Swedish Corrosion Institute: Stockholm, Sweden, 1998; p. 49.

13. Tidblad, J.; Mikhailov, A.A.; Kucera, V. Unified Dose-Response Functions after 8 Years of Exposure. In Quantification of Effects of Air Pollutants on Materials; UN ECE Workshop Proceedings; Umweltbundesamt: Berlin, Germany, 1999; pp. 77-86.

14. Tidblad, J.; Kucera, V.; Mikhailov, A.A.; Henriksen, J.; Kreislova, K.; Yaites, T.; Stöckle, B.; Schreiner, M. UN ECE ICP Materials. Dose-response functions on dry and wet acid deposition effects after 8 years of exposure. Water Air Soil Pollut. 2001, 130, 1457-1462. [CrossRef]

15. Tidblad, J.; Mikhailov, A.A.; Kucera, V. Acid Deposition Effects on Materials in Subtropical and Tropical Climates. Data Compilation and Temperate Climate Comparison; KI Report 2000:8E; Swedish Corrosion Institute: Stockholm, Sweden, 2000; pp. 1-34.

16. Tidblad, J.; Mikhailov, A.A.; Kucera, V. Application of a Model for Prediction of Atmospheric Corrosion for Tropical Environments. In Marine Corrosion in Tropical Environments; Dean, S.W., Delgadillo, G.H., Bushman, J.B., Eds.; American Society for Testing and Materials: West Conshohocken, PA, USA, 2000; p. 18. 
17. Tidblad, J.; Kucera, V.; Mikhailov, A.A.; Knotkova, D. Improvement of the ISO Classification System Based on Dose-Response Functions Describing the Corrosivity of Outdoor Atmospheres. In Outdoor Atmospheric Corrosion, ASTM STP 1421; Townsend, H.E., Ed.; American Society for Testing and Materials: West Conshohocken, PA, USA, 2002; p. 73.

18. Corrosion of Metals and Alloys-Corrosivity of Atmospheres-Classification, Determination and Estimation; ISO 9223:2012(E); International Standards Organization: Geneva, Switzerlands, 2012.

19. Cai, J.; Cottis, R.A.; Lyon, S.B. Phenomenological modelling of atmospheric corrosion using an artificial neural network. Corros. Sci. 1999, 41, 2001-2030. [CrossRef]

20. Pintos, S.; Queipo, N.V.; de Rincon, O.T.; Rincon, A.; Morcillo, M. Artificial neural network modeling of atmospheric corrosion in the MICAT project. Corros. Sci. 2000, 42, 35-52. [CrossRef]

21. Diaz, V.; Lopez, C. Discovering key meteorological variables in atmospheric corrosion through an artificial neural network model. Corros. Sci. 2007, 49, 949-962. [CrossRef]

22. Kenny, E.D.; Paredes, R.S.C.; de Lacerda, L.A.; Sica, Y.C.; de Souza, G.P.; Lazaris, J. Artificial neural network corrosion modeling for metals in an equatorial climate. Corros. Sci. 2009, 51, 2266-2278. [CrossRef]

23. Reddy, N.S. Neural Networks Model for Predicting Corrosion Depth in Steels. Indian J. Adv. Chem. Sci. 2014, 2, 204-207.

24. Knotkova, D.; Kreislova, K.; Dean, S.W. ISOCORRAG International Atmospheric Exposure Program: Summary of Results; ASTM Series 71; ASTM International: West Conshohocken, PA, USA, 2010.

25. Morcillo, M. Atmospheric corrosion in Ibero-America. The MICAT project. In Atmospheric Corrosion; Kirk, W.W., Lawson, H.H., Eds.; ASTM STP 1239; American Society for Testing and Materials: Philadelphia, PA, USA, 1995; pp. 257-275.

26. Panchenko, Y.M.; Shuvakhina, L.N.; Mikhailovsky, Y.N. Atmospheric corrosion of metals in Far Eastern regions. Zashchita Metallov 1982, 18, 575-582. (In Russian).

27. Knotkova, D.; Vlckova, J.; Honzak, J. Atmospheric Corrosion of Weathering Steels. In Atmospheric Corrosion of Metals; Dean, S.W., Jr., Rhea, E.C., Eds.; ASTM STP 767; American Society for Testing and Materials: Philadelphia, PA, USA, 1982; pp. 7-44.

28. Tidblad, J.; Mikhailov, A.A.; Kucera, V. Model for the prediction of the time of wetness from average annual data on relative air humidity and air temperature. Prot. Met. 2000, 36, 533-540. [CrossRef]

29. Feliu, S.; Morcillo, M.; Feliu, J.S. The prediction of atmospheric corrosion from meteorological and pollution parameters. I. Annual corrosion. Corros. Sci. 1993, 34, 403-422. [CrossRef]

30. Panchenko, Y.M.; Marshakov, A.I.; Nikolaeva, L.A.; Kovtanyuk, V.V.; Igonin, T.N.; Andryushchenko, T.A. Comparative estimation of long-term predictions of corrosion losses for carbon steel and zinc using various models for the Russian territory. CEST 2017, 52, 149-157. [CrossRef] 